Konrad-Zuse-Zentrum

für Informationstechnik Berlin

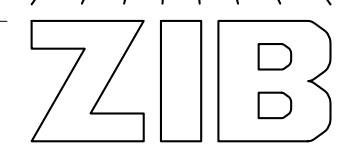

H.M.T.Boer, C.STÖTzel, S.RÖBlitz, P.DeUflhard, R.F.VEERKAMP, H.WOELDERS

A simple mathematical model of the bovine estrous cycle: follicle development and endocrine interactions 



\title{
A simple mathematical model of the bovine estrous cycle: follicle development and endocrine interactions
}

\author{
H.M.T.Boer *† C.Stötzel ${ }^{\ddagger} \quad$ S.Röblitz ${ }^{\ddagger} \quad$ P.Deuflhard ${ }^{\ddagger}$ \\ R.F.Veerkamp* H.Woelders*
}

May 27, 2010

\begin{abstract}
Bovine fertility is the subject of extensive research in animal sciences, especially because fertility of dairy cows has declined during the last decades. The regulation of estrus is controlled by the complex interplay of various organs and hormones. Mathematical modeling of the bovine estrous cycle could help in understanding the dynamics of this complex biological system. In this paper we present a mechanistic mathematical model of the bovine estrous cycle that includes the processes of follicle and corpus luteum development and the key hormones that interact to control these processes. The model generates successive estrous cycles of 21 days, with three waves of follicle growth per cycle. The model contains 12 differential equations and 54 parameters. Focus in this paper is on development of the model, but also some simulation results are presented, showing that a set of equations and parameters is obtained that describes the system consistent with empirical knowledge. Even though the majority of the mechanisms that are included in the model are based on relations that in literature have only been described qualitatively (i.e. stimulation and inhibition), the output of the model is surprisingly well in line with empirical data. This model of the bovine estrous cycle could be used as a basis for more elaborate models with the ability to study effects of external manipulations and genetic differences.
\end{abstract}

AMS MSC 2000: 92C42, 92C30, 90C31, 65L09

Keywords: cow, reproduction, hormone patterns, differential equations, systems biology

*Animal Breeding and Genomics Center, Wageningen UR Livestock Research, 8200 AB Lelystad, The Netherlands

${ }^{\dagger}$ Adaptation Physiology Group, Department of Animal Sciences, Wageningen University, 6700 AH Wageningen, The Netherlands

¥Zuse Institute Berlin (ZIB), Takustraße 7, 14195 Berlin, Germany

$\S$ Corresponding author. E-mail: susanna.roeblitz@zib.de 


\section{Contents}

1 Introduction 3

2 Biological background 4

2.1 The bovine estrous cycle . . . . . . . . . . . . . . . . . 4

2.2 Follicle development . . . . . . . . . . . . . . . . . . . 4

2.3 Follicular waves . . . . . . . . . . . . . . . . . 5

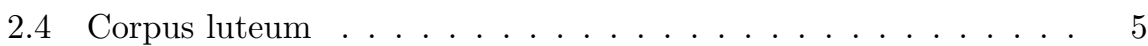

2.5 Dynamics of ovarian and uterine hormones . . . . . . . . 6

2.5 .1 Estradiol . . . . . . . . . . . . . . . . 6

2.5 .2 Inhibin . . . . . . . . . . . . . . . . 6

2.5.3 Progesterone . . . . . . . . . . . . . . . . 7

2.5.4 Prostaglandin $\mathrm{F} 2 \alpha \ldots \ldots \ldots \ldots$

2.6 Dynamics of hypothalamic and pituitary hormones . . . . . . 8

2.6.1 Gonadotropin releasing hormone . . . . . . . . . . 8

2.6 .2 Luteinizing hormone . . . . . . . . . . . . . . . . 8

2.6.3 Follicle stimulating hormone . . . . . . . . . . . . . . 9

3 Mathematical formulation 9

3.1 Hill functions . . . . . . . . . . . . . . . . . . . . . . . . 11

3.2 Model equations . . . . . . . . . . . . . . . . . . . . . 11

3.3 Parameter identification and sensitivity analysis . . . . . . . . 14

$\begin{array}{lll}4 & \text { Simulation results } & 17\end{array}$

5 Discussion and Outlook 20

A List of Hill functions $\quad 22$

B List of parameters $\quad 23$

C List of equations $\quad 25$ 


\section{Introduction}

Systems biology is a relatively new research area in the field of animal sciences. It aims at understanding how the various components of a biological system function together, rather than investigating only individual parts. One approach is the translation of a conceptual biological model into a set of mathematical equations that represent the dynamic relations between system components. The purpose of building such mathematical models is to interpret and predict the dynamics of complex biological systems, and to identify new research questions.

One example of a dynamic biological system is the bovine estrous cycle, the hormonally controlled recurrent periods when the cow is preparing for reproduction by producing a fertilizable oocyte. Concurrent with selection for increased milk yield, a decrease in dairy cow fertility has been observed during the last decades (for reviews see $[59,75]$ ). This decline in fertility is shown by e.g. alterations in hormone patterns during the estrous cycle, reduced expression of estrous behavior and lower conception rates [79]. However, it is hard to understand which underlying mechanisms cause this decline in fertility. The regulation of estrus is controlled by the interplay of various organs and hormones. Mathematical modeling of the involved mechanisms is expected to improve insight in the biological processes underlying the bovine estrous cycle, and could thereby help to find causes of declined fertility in dairy cows [11].

Although the endocrine and physiologic regulation of the bovine estrous cycle is studied extensively, mathematical models of cycle regulation are scarce and of limited scope $[49,70]$. A number of models have been developed for other ruminant species, especially ewes $[13,35]$, but these models do not contain all the key players that are required to simulate follicle development and the accompanying hormone levels throughout consecutive cycles. A model that integrates the major tissues and hormones involved, and that is able to simulate the dynamics of follicular development, has been developed for the human menstrual cycle [61]. This model describes the dynamics of hormones, enzymes, receptors, and follicular phases throughout the cycle in a set of differential equations.

The objective of the work described in this paper was to develop a mathematical model of the dynamics of the bovine estrous cycle on individual cow level, that is able to simulate follicle development and the accompanying fluctuations in hormone concentrations. Physiologic and endocrine mechanisms that regulate the cycle are very similar between human and cows. Therefore, some mechanisms of the human model in [61] could be used (although sometimes with simplifications), and extended with other mechanisms like follicular wave emergence and corpus luteum regression.

Focus in this paper is on the model development. Section 2 describes the biological mechanisms of the bovine estrous cycle and how these mechanisms are incorporated in the model. In Section 3, the mathematical description and all model equations and parameters are given. Simulation results are presented in Section 4, showing that a set of equations and parameters is obtained that describes the system consistent with biological data for cows. In Section 5, it is discussed how the current model could be applied and extended. 


\section{Biological background}

\subsection{The bovine estrous cycle}

The main tissues and organs involved in the regulation of the estrous cycle are the ovaries, the uterus, the hypothalamus and the anterior pituitary. These organs interact via hormones in the blood (reviewed in [11]). In the bovine, most estrous cycles have two or three waves in which a cohort of follicles start to grow and produce estradiol (E2). The first one or two waves produce a dominant follicle that does not ovulate, but undergoes regression under influence of progesterone $(\mathrm{P} 4)$. The dominant follicle that develops in the last wave becomes the ovulatory follicle. The average duration of the bovine estrous cycle is 20 days for 2 -wave and 22 days for 3 -wave cycles (reviewed in [3]). During pro-estrus, when the corpus luteum (CL) is regressed and the concentration of P4 is decreased, the dominant follicle, deviated from a cohort of antral follicles, develops and matures under the influence of follicle stimulating hormone (FSH) and luteinizing hormone ( $\mathrm{LH})$ secreted from the pituitary. FSH plays an important role in the beginning of follicular growth, while LH is important for maturation up to ovulation. During development to preovulatory size, the dominant follicle secretes increasing amounts of estradiol (E2), and also inhibin (Inh), which inhibits FSH synthesis and, hence, inhibits the growth of subordinate follicles [10, 27]. E2 inhibits gonadotropin releasing hormone (GnRH) secretion from the hypothalamus and therefore LH secretion from the pituitary throughout most of the cycle. However, during pro-estrus, elevated E2 levels increase the secretion of GnRH, which, together with direct effects of E2 on the pituitary, triggers the LH surge, which induces ovulation. Once an oocyte is successfully ovulated, the remains of the follicle form a new P4-producing CL. $\mathrm{P} 4$ maintains the readiness of the endometrium for receiving the embryo. If conception has failed, the CL regresses under influence of prostaglandin F $2 \alpha$ (PGF2 $\alpha$ ) produced in the endometrium [47], P4 levels decrease, and the cycle restarts (reviewed in [11]).

\section{$2.2 \quad$ Follicle development}

Follicle development is controlled by changes in hormone levels. In each cycle, one follicle ovulates, while all other growing follicles go into regression at a certain stage of their development. The follicles produce E2 and Inh, which are released into peripheral blood. Different follicles are recruited, growing, and regressing in each cycle and in each wave. However, total E2 and Inh production capacity is modeled as a continuous function throughout subsequent waves and cycles, sometimes rising, sometimes falling, representing the total amount of hormone production of the follicles present at any moment. Small follicles of an emerging cohort may release very small amounts of E2 and Inh per follicle, but taken together, this amount is not negligible. Furthermore, there is always a medium-size or large follicle present [36, 80, 81], which results in a basal hormone production throughout the cycle. The capacity of follicles to produce E2 and Inh is denoted as "follicular function" in the rest of this paper. 


\section{$2.3 \quad$ Follicular waves}

Two different patterns of follicle development are identified in mammals. In humans (and rats and pigs), the development of follicles to ovulatory size occurs only during the follicular phase, while in cattle (and sheep and horses), development of follicles to ovulatory or near-ovulatory size occurs throughout the cycle [26]. A normal bovine estrous cycle includes two or three wave-like patterns of follicle development. The ovaries contain a pool of primordial follicles, consisting of an immature oocyte surrounded by a single layer of epithelial cells. Follicle growth starts with the transformation of primordial to primary follicles. Under influence of FSH, a cohort of 8-41 growing follicles emerge [3]. One follicle becomes the dominant follicle and continues to grow [3]. Growing follicles produce increasing amounts of Inh. Inh suppresses FSH secretion, and above a certain Inh production this will cause a decline in FSH serum levels. Inh production declines with ovulation or regression of the dominant follicle, thereby allowing FSH to rise again. This FSH rise induces the emergence of the next follicular wave [27]. Follicle growth is associated with increased mRNA expression for LH and FSH receptors and steroidogenic enzymes, which regulates the follicles ability to produce steroid hormones [6]. Approximately two days after cohort recruitment, one follicle of $8-9 \mathrm{~mm}$ in diameter is selected to grow to $15 \mathrm{~mm}$ [6]. The growing dominant follicle secretes increased amounts of Inh, which suppresses FSH release, thereby inhibiting the growth of subordinate follicles. Because the dominant follicle increases its sensitivity for FSH and LH, it continues to grow, even when FSH levels are decreased $[7,28]$. Follicular stages differ in expression of steroidogenic enzymes and therefore differ in E2 production. Enzyme concentrations in follicles depend on LH and FSH concentrations in the blood and on concentration of activated LH and FSH receptors at the follicle. Deviation of the dominant follicle from the cohort of growing follicles is associated with increased FSH and LH receptor binding, activating the enzymes that catalyze steroidogenesis, resulting in increased E2 production and higher E2 serum levels. If $\mathrm{P} 4$ remains at luteal levels, the dominant follicle goes into regression. Follicle regression is associated with down-regulation in mRNA expression of receptors for LH and FSH and steroidogenic enzymes, resulting in declined E2 production [6]. Therefore, neither the LH surge nor ovulation take place $[3,6]$. The dominant follicle that is present at the onset of CL regression becomes the ovulatory follicle $[3,6]$. In the preovulatory follicle, the LH peak induces a shift from E2 to $\mathrm{P} 4$ production [18] by changing the expression of steroidogenic enzymes $[6,72]$. Follicle development is modeled as growth of E2 and Inh producing tissue. In the model, emergence of a follicular wave is induced when FSH exceeds a threshold. This threshold for FSH becomes lower when follicles become larger, representing that larger follicles are more sensitive to FSH. Follicle regression is promoted by high P4 levels and by the LH surge (Equation 7). The current model comprises three follicular waves per cycle: two non-ovulatory waves and a third wave that is ovulatory.

\subsection{Corpus luteum}

The LH surge at the end of the third wave induces ovulation of the dominant follicle and differentiation of cells of the follicular wall into luteal cells [51]. Continued CL growth is stimulated by autocrine and paracrine mechanisms 
[68]. The CL develops within 2-3 days after ovulation, grows until a maximum diameter of about $30 \mathrm{~mm}$, and starts to regress at day $17-18$ of the cycle [50, 73], although P4 levels may start to decline earlier [81]. The primary function of the $\mathrm{CL}$ is $\mathrm{P} 4$ secretion. Maintenance of $\mathrm{P} 4$ secretion is prerequisite for pregnancy. If pregnancy does not occur, regression of the CL is required to allow the next ovulation. CL regression is induced by pulsatile PGF $2 \alpha$ secretion from the uterus [51]. In each cycle a new CL develops, but CL development is modeled as a continuous function of $\mathrm{P} 4$ producing tissue. The capacity of the CL to produce P4 is denoted as "CL function" in the rest of this paper. In the model, CL development is induced by the LH surge. A threshold and delay are incorporated in the effect of $\mathrm{LH}$ on the $\mathrm{CL}$, to account for the time required for the process of transition from follicle to CL. If the CL reaches a certain size, it continues to grow without further stimulation by LH. A couple of days after P4 reaches a threshold, PGF2 $\alpha$ rises and induces a decline in CL function and thereby in P4 serum levels (Equation 9).

\subsection{Dynamics of ovarian and uterine hormones}

The production of E2, Inh, P4 and PGF2 $\alpha$ depends largely on follicle and CL stage. The follicle is the main producer of $\mathrm{E} 2$ and Inh, while the CL mainly produces P4, and PGF2 $\alpha$ is produced in the endometrium. E2, P4 and Inh are transported via peripheral blood. Transport of PGF $2 \alpha$ to the ovaries occurs via a counter current mechanism between the uterine vein and the ovarian artery [39], but concentration is assumed to be represented by peripheral PGFM, the main PGF2 $\alpha$ metabolite $[43,82]$.

\subsubsection{Estradiol}

E2 affects LH synthesis and release [31] and FSH release [7, 41]. Furthermore, E2 plays an important role in the expression of estrous behavior (reviewed in [11]). E2 concentration in follicular fluid increases when follicles grow, and the concentration in fluid of ovulatory follicles is twice as high compared to non-ovulatory follicles [3]. Serum peak concentrations measured around estrus range from $6.8-16.1 \mathrm{pg} / \mathrm{ml}[10,23,24,30,37,80]$. E2 serum levels are higher in ovulatory compared to non-ovulatory waves [10,23]. This suggests that the preovulatory follicle has the largest capacity to produce and release E2, although its maximum size is not significantly different from the maximum size of nonovulatory dominant follicles. E2 production and conductivity of E2 efflux to blood is thus not constant throughout the cycle, but appears to change under influence of differential gene expression patterns affected by LH, FSH, P4 and PGF $2 \alpha[2,1]$. Considering the results in $[2,1]$, where a better vascularity of the ovulatory follicle is reported, it is reasonable that the ovulatory follicle can secrete more E2 than non-ovulatory follicles and, consequently, E2 serum levels are highest at estrus. In our model, the rate of E2 production and release to the blood is taken as proportional to follicular function (Equation 11).

\subsubsection{Inhibin}

Inh inhibits FSH synthesis and thus release [27]. Inh production is increased when follicles grow. Inh secretion by dominant follicles suppresses FSH serum 
levels and thereby reduces the growth of subordinate follicles [48]. The dominant follicle expresses more LH and FSH receptors, which means that the sensitivity of the follicle for LH and FSH is increased, and it can therefore continue to grow even when LH and FSH serum levels are low [25]. FSH induces the emergence of a new follicular wave. However, when follicles grow, also Inh concentration grows, which suppresses FSH secretion, and from a certain level on thus causes a decline in FSH serum levels. Inh production declines with ovulation or regression of the dominant follicle, thereby allowing FSH to rise again, and a new follicular wave will emerge [7]. Peak Inh levels in serum are on average $332 \mathrm{pg} / \mathrm{ml}$ in nonovulatory and $464 \mathrm{pg} / \mathrm{ml}$ in ovulatory waves respectively, and minimum Inh levels are about $180 \mathrm{pg} / \mathrm{ml}$ [55]. There are different forms of inhibin, but only inhibin A is considered in the model, as it is the predominant form in bovine follicular fluid [7]. In our model, Inh production rate is taken as proportional to follicular function (Equation 12).

\subsubsection{Progesterone}

Serum P4 concentration determines if a dominant follicle will be able to develop to an ovulatory follicle. Ovulation of the dominant follicle of the first two waves of the cycle is inhibited because P4 levels are high, and the follicle will regress. The dominant follicle in the third wave will not regress, because P4 drops below a certain threshold. Ovulation can then take place because the inhibiting effect of $\mathrm{P} 4$ on the LH surge is removed [43]. The CL is the main source of $\mathrm{P} 4$. P4 levels decline as a result of CL regression [3]. P4 inhibits the luteolytic signal [43], and controls the life span of the CL by regulating uterine PGF2 $\alpha$ secretion [9]. Receptors for E2 and P4 are highly expressed in the CL in the early luteal phase, which probably stimulates $\mathrm{P} 4$ secretion and prevents apoptosis [65]. Serum P4 concentration is near to zero around estrus and high during the luteal phase, with average peak levels ranging from 4.1-9.9 ng/ml $[4,17,23,38,71]$. A high correlation between CL diameter and P4 output was reported in [58, 64, 81]. However, Adams [4] found a correlation between CL size and $\mathrm{P} 4$ serum levels in the early luteal phase only, which could be due to changes in CL vascularity during the cycle, resulting in changes in $\mathrm{P} 4$ releasing capacity $[46,50]$. In our model, the rate of $\mathrm{P} 4$ release into the blood is taken as proportional to CL function (Equation 10).

\subsubsection{Prostaglandin F2 $\alpha$}

Pulsatile PGF $2 \alpha$ release from the uterus induces CL regression, and is regulated by oxytocin (OT), P4 and E2 [67]. In the first half of the cycle, P4 inhibits expression of genes for E2 synthesis and OT receptors in the endometrium, to prevent a too early release of PGF $2 \alpha$ pulses. Simultaneously, P4 stimulates synthesis of enzymes required for PGF $2 \alpha$ production. In the second half of the cycle, expression of $\mathrm{P} 4$ receptors is down-regulated and expression of OT receptors is up-regulated, resulting in a gradual decrease in the suppression of PGF2 $\alpha[22]$. As a result of down-regulation of $\mathrm{P} 4$ receptors in the hypothalamus, OT secretion increases, which induces uterine pulses of PGF2 $\alpha$ [47]. At the end of the luteal phase, PGF2 $\alpha$ is secreted in 5-8 discrete pulses with 6-8h interval [67]. A broad range of PGF2 $\alpha$ levels is reported in literature, but in general peak levels are 3-fold higher than basal levels. Average basal and peak levels 
are $20-40 \mathrm{pg} / \mathrm{ml}$ and $80-150 \mathrm{pg} / \mathrm{ml}$, respectively [22, 44, 66], but higher values (300 and $700 \mathrm{pg} / \mathrm{ml}$ for basal and peak levels respectively) were reported in [5]. Exposure to substantial amounts of $\mathrm{P} 4$ must last for a couple of days to induce PGF $2 \alpha$ pulses [45]. In the model, PGF2 $\alpha$ increases a couple of days after P4 levels reach a threshold. P4 with another delay induces the decline in PGF2 $\alpha$ a few days later (Equation 8).

\subsection{Dynamics of hypothalamic and pituitary hormones}

Effects of P4 and E2 on LH and FSH synthesis and release occur directly on the anterior pituitary, but also via pulsatile $\mathrm{GnRH}$ release. $\mathrm{GnRH}$ is released from the hypothalamus to the anterior pituitary via the portal blood system. LH is required for normal luteal function and follicle growth, and FSH is important during early follicular development.

\subsubsection{Gonadotropin releasing hormone}

Pulsatile signaling of GnRH regulates LH and FSH release, and controls LH secretion [56]. Because GnRH induces the LH surge, it indirectly induces ovulation [74]. The GnRH pulse generator is located in the hypothalamus and is modulated by P4 and E2 [32]. During the luteal phase, both P4 and E2 suppress the activity of the GnRH pulse generator. During pro-estrus however, elevated E2 induces a GnRH surge [31, 32]. GnRH is produced and stored in hypothalamic neurons and released in pulses when these neurons are stimulated by high E2 concentrations. GnRH is released from the hypothalamus into the portal circulation of the pituitary and binds to $\mathrm{GnRH}$ receptors of the anterior pituitary [76]. Low P4 levels, combined with increased E2 serum levels and pulsatile $\mathrm{GnRH}$ release up-regulates expression of $\mathrm{GnRH}$ receptors [32, 76], which will make the pituitary more sensitive to GnRH. GnRH pulsatility is important because prolonged constant GnRH exposure leads to down-regulation of GnRH receptor [76, 77]. GnRH pulse frequency affects height of the LH peak [76], and also treatment with a single GnRH injection can increase LH peak height [14]. Administration of GnRH induces an LH surge within 30 minutes [54]. In the model, GnRH stimulates LH, resulting in an LH surge concurrently with the GnRH surge. GnRH synthesis is taken constant as long as the amount of GnRH in the hypothalamus is below a threshold (Equation 1). GnRH release is inhibited when P4 levels are above a threshold and when both P4 and E2 levels are above a threshold. GnRH release switches when P4 levels are low and E2 reaches a threshold (Equation 1b), resulting in a surge of GnRH. GnRH concentration in the pituitary depends on GnRH amount released from the hypothalamus, and is further increased by high E2 levels, representing that E2 up-regulates expression of GnRH receptors (Equation 2).

\subsubsection{Luteinizing hormone}

LH is required for normal CL function and follicle development [76]. The LH surge at the day before ovulation induces ovulation of the ovulatory follicle and formation of the CL. The LH surge is caused by continued increase in serum E2 during the ovulatory wave. Besides direct effects of E2 on the pituitary, E2 stimulates the LH surge because it stimulates GnRH [32]. The LH surge will 
shut down E2 and Inh production capacity of the ovulatory follicle [12, 81] and induces a shift from E2 to P4 production [19]. LH level in the blood declines because the LH content of the anterior pituitary is reduced and further LH synthesis therein and release to the blood is decreased because E2 is decreased. Experiments in ewes showed that LH content of the anterior pituitary is highest at the day before ovulation and is declined by $89 \%$ two days after ovulation [69].

High P4 levels prevent ovulation in the first two follicular waves, because $\mathrm{P} 4$ suppresses the release of $\mathrm{LH}$ via the inhibition of the GnRH pulse generator [8]. Additionally, high P4 levels decrease pituitary sensitivity to E2, thereby increasing the amount of E2 required to induce an LH surge above physiological levels [32].

Basal LH levels are about 1-2 ng/ml, and average peak levels of the LH surge range from $6.8-14.5 \mathrm{ng} / \mathrm{ml}[10,23,40]$, and even higher peak values were found in e.g. [18]. In the model, LH synthesis is stimulated by E2 and inhibited by P4 (Equation 5a). Besides a small basal LH release, there is a surge of LH when $\mathrm{GnRH}$ in the pituitary reaches a threshold (Equation $5 \mathrm{~b}$ ).

\subsubsection{Follicle stimulating hormone}

Each follicular wave is initiated by an increase in FSH release from the anterior pituitary [29]. Growth of small follicles is dependent on FSH [48] . FSH synthesis is inhibited by Inh produced by growing follicles [7]. P4 and E2 modulate FSH release via effects on the anterior pituitary and on the $\mathrm{GnRH}$ pulse generator in the hypothalamus. Some studies in cows show an FSH peak concurrently with the LH surge [38, 40], while other studies fail to show a clear peak $[4,10,24]$. Basal FSH levels are about $5-10 \mathrm{ng} / \mathrm{ml}$, and peak levels about $15 \mathrm{ng} / \mathrm{ml}[10,24]$. In our model, FSH synthesis in the pituitary is increased when Inh levels are below a threshold (Equation 3a). FSH release from the pituitary to the blood is stimulated by $\mathrm{P} 4$ and $\mathrm{GnRH}$, and inhibited by E2 (Equation 3b).

\section{Mathematical formulation}

The mathematical approach used for the bovine model is comparable to the approach used for the model of the human menstrual cycle [60], which has been developed at the Zuse Institute. The system is considered in four compartments: hypothalamus, anterior pituitary, ovaries and uterus, connected through peripheral and portal blood (Figure 1). The model includes the processes of follicle and CL development and the key hormones that interact to control these processes as described in Section 2. The complete mechanisms are shown in Figure 2 .

Based on these mechanisms, 12 ordinary differential equations (ODEs) with 54 parameters are formulated. If necessary, time delays are incorporated to model the time between events and their effects, representing the duration of intermediate steps in biological processes. In this case, the ODE is turned into a delay differential equation (DDE). To solve the system of differential equations, we use the solver RADAR5 [33], which has been designed for the solution of stiff delay differential equations. 


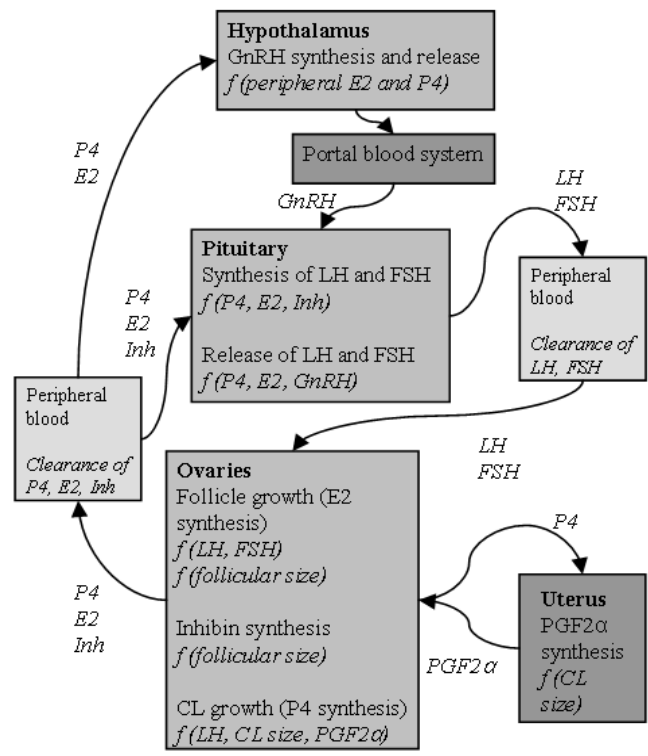

Figure 1: Schematic representation of the compartments in the model of the bovine estrous cycle.

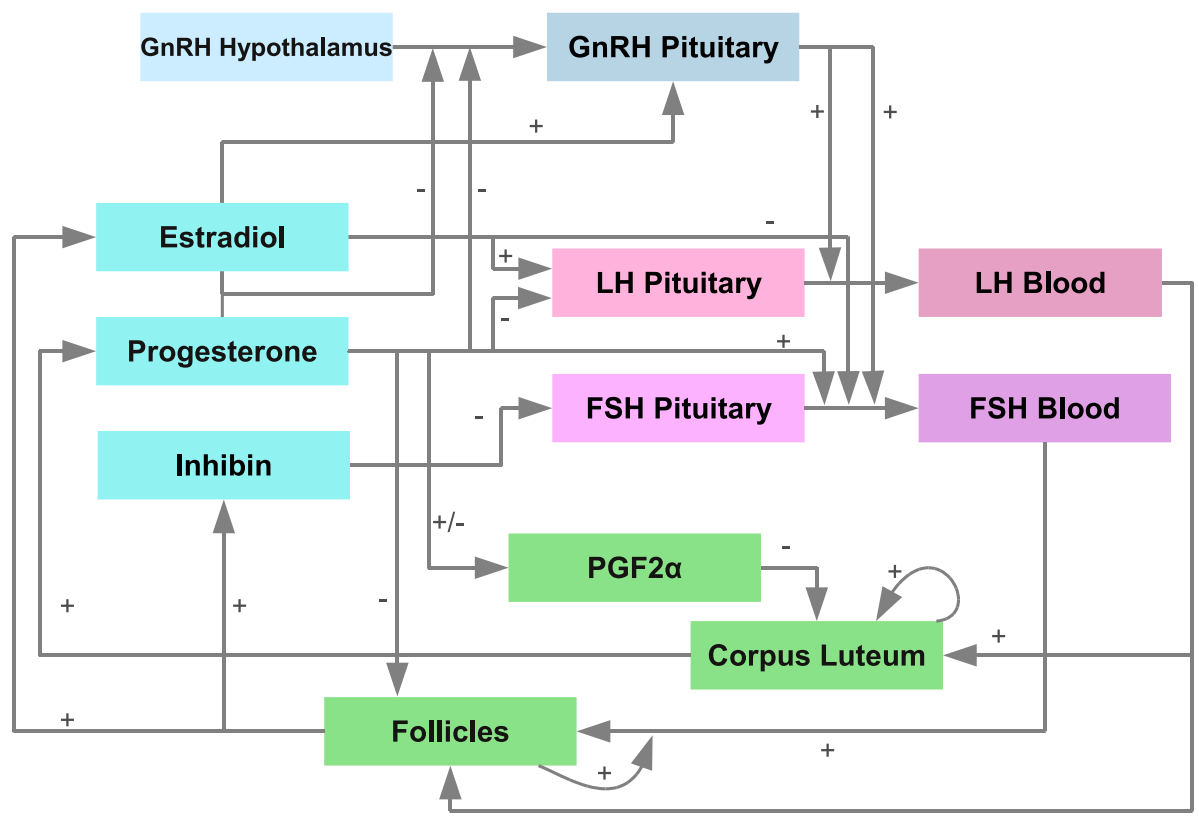

Figure 2: Complete mechanisms of the bovine model. Boxes represent the 12 key components of the system. Differential equations are derived for these 12 components. Arrows denote functional dependencies. Stimulating and inhibiting effects are indicated by + and - respectively. 


\subsection{Hill functions}

Because the exact mechanisms are often not known or more specific than necessary, Hill functions are used to model stimulatory and inhibitory effects of the hormones. They are used whenever there is a nonlinear relation between two substances. A Hill function is a sigmoidal function between zero and one, which switches at a specified threshold from one level to the other with a specified steepness. Positive Hill functions are used for stimulating effects and are defined as

$$
h^{+}(S(t) ; T, n):=\frac{S(t)^{n}}{T^{n}+S(t)^{n}} .
$$

$S(t)$ represents the effector, $T$ the threshold for change of behavior, and $n$ controls the steepness of the curve. Negative Hill functions are used for inhibitory effects and are defined as

$$
h^{-}(S(t) ; T, n):=\frac{T^{n}}{T^{n}+S(t)^{n}} .
$$

Here, the value of the function has its maximum at the lowest value of the initiating substrate $S(t)$, and switches to zero if this substrate passes the threshold $T$.

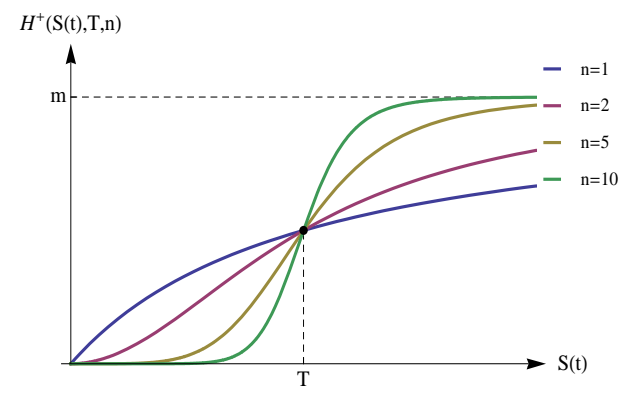

Figure 3: Scaled positive Hill functions with different steepness.

Whenever a Hill function is used, it is provided with another parameter $m$ that controls the height of the switch. This parameter serves as maximum stimulatory respectively inhibitory effect. For abbreviation of notation, we use $H^{+}(S)$ instead of $m \cdot h^{+}(S(t) ; T, n)$. We usually choose the steepness coefficient $n=2$, but, when appropriate, we set $n=1,5$, or 10 to capture smoother or steeper effects. The complete set of Hill functions is specified in A, and parameter values can be found in B.

\subsection{Model equations}

The amount of GnRH in the hypothalamus is a result of synthesis in the hypothalamus and release into the pituitary,

$$
\frac{d}{d t} G n R H_{H y p o}(t)=S y n_{G n R H}(t)-\operatorname{Rel}_{G n R H}(t) .
$$

GnRH synthesis depends on its current level in the hypothalamus. If this level approaches a specified threshold, synthesis decreases to zero. This effect is 
modeled as logistic growth,

$$
\operatorname{Syn}_{G n R H}(t)=c_{G n R H, 1} \cdot\left(1-\frac{G n R H_{H y p o}(t)}{G n R H_{\text {Hypo }}^{\max }}\right) .
$$

As long as GnRH is far below its maximum, the factor $1-\frac{G n R H_{\text {Hypo }}(t)}{G n R H_{\text {Hypo }}}$ has only a small impact. The release of GnRH from the hypothalamus to the pituitary is dependent on its current level in the hypothalamus. E2 inhibits GnRH release during the luteal phase, i.e. if $\mathrm{P} 4$ and $\mathrm{E} 2$ are high at the same time, described by $H_{1}^{-}\left(P_{4} \& E_{2}\right) . H_{1}^{-}\left(P_{4} \& E_{2}\right)$ denotes the sum of two Hill functions minus their product, and inhibits GnRH release only if both substrates are above their threshold. Additionally, the release of GnRH is inhibited by $\mathrm{P} 4$ only,

$$
\operatorname{Rel}_{G n R H}(t)=\left(H_{1}^{-}\left(P_{4} \& E_{2}\right)+H_{2}^{-}\left(P_{4}\right)\right) \cdot G n R H_{H y p o}(t) .
$$

Changes in GnRH amount in the pituitary are dependent on the released amount from the hypothalamus, but also on the presence of E2. E2 increases the number of GnRH receptors in the pituitary. This effect is included in the equation as a positive Hill function. GnRH clearance from pituitary portal blood is proportional to the GnRH level in the pituitary, i.e. GnRH clearance is represented by $c_{G n R H, 2} \cdot G n R H_{P i t}(t)$, in which $c_{G n R H, 2}$ is a constant,

$$
\frac{d}{d t} G n R H_{P i t}(t)=\operatorname{Rel}_{G n R H}(t) \cdot H_{3}^{+}\left(E_{2}\right)-c_{G n R H, 2} \cdot G n R H_{P i t}(t) .
$$

FSH is synthesized in the pituitary and released into the blood,

$$
\frac{d}{d t} F S H_{P i t}(t)=\operatorname{Syn}_{F S H}(t)-\operatorname{Rel}_{F S H}(t) .
$$

FSH synthesis rate in the pituitary is only dependent on delayed Inh, as in Harris (2001). FSH is synthesized when the Inh level is low, i.e. high Inh levels inhibit FSH synthesis, which is included as a negative Hill function,

$$
\operatorname{Syn}_{F S H}=H_{4}^{-}\left(I n h_{\tau}\right) .
$$

The index $\tau$ stands for a delayed effect of Inh, i.e. Inh is considered at time $t-\tau$. FSH release from the pituitary to the blood is stimulated by $\mathrm{P} 4$ and $\mathrm{GnRH}$, and inhibited by E2,

$$
\operatorname{Rel}_{F S H}=\left(H_{5}^{+}\left(P_{4}\right)+H_{6}^{-}\left(E_{2}\right)+H_{7}^{+}\left(G n R H_{P i t}\right)\right) \cdot F S H_{P i t}(t) .
$$

Concluding, FSH serum level is a result of the difference between the released amount from the pituitary and clearance in the blood,

$$
\frac{d}{d t} F S H_{B l o o d}(t)=\operatorname{Rel}_{F S H}(t)-c_{F S H} \cdot F S H_{B l o o d}(t),
$$

where $c_{F S H}$ is the FSH clearance rate constant.

Like FSH, the LH serum level depends on synthesis in the pituitary, release into the blood and clearance thereof,

$$
\frac{d}{d t} L H_{P i t}(t)=\operatorname{Syn}_{L H}(t)-\operatorname{Rel}_{L H}(t) .
$$


LH synthesis in the pituitary is stimulated by $\mathrm{E} 2$ and inhibited by $\mathrm{P} 4$,

$$
\operatorname{Syn}_{L H}(t)=H_{8}^{+}\left(E_{2}\right)+H_{9}^{-}\left(P_{4}\right) .
$$

We assume a low constant basal LH release $b_{L H}$ from the pituitary into the blood. On top of that, LH release is stimulated by GnRH,

$$
\operatorname{Rel}_{L H}(t)=\left(b_{L H}+H_{10}^{+}\left(G n R H_{P i t}\right)\right) \cdot L H_{P i t}(t) .
$$

Summarizing, LH in the blood is obtained as

$$
\frac{d}{d t} L H_{\text {Blood }}(t)=\operatorname{Rel}_{L H}(t)-c_{L H} \cdot L H_{B l o o d}(t),
$$

where $c_{L H}$ is the LH clearance rate constant.

Follicular function is stimulated by FSH, whereas its decrease is promoted by $\mathrm{P} 4$ and the LH surge,

$$
\frac{d}{d t} \operatorname{Foll}(t)=H_{11}^{+}(F S H)-\left(H_{12}^{+}\left(P_{4}\right)+H_{13}^{+}\left(L H_{\text {Blood }}\right)\right) \cdot \operatorname{Foll}(t) .
$$

The sensitivity of the follicles to respond to FSH grows with their size. In the model, the threshold of FSH to stimulate the follicular function decreases with increasing follicular function. For this effect of a rising FSH sensitivity, a negative Hill function is included to control the threshold of FSH,

$$
\widetilde{T}_{F S H}^{\text {Foll }}(t):=T_{F S H}^{\text {Foll }} \cdot h^{-}\left(\text {Foll }(t) ; T_{\text {Foll }}^{F S H}, 1\right),
$$

and the Hill function for the effect of FSH on follicular function becomes

$$
H_{11}^{+}(F S H):=m_{F S H}^{F o l l} \cdot h^{+}\left(F S H_{\text {Blood }}(t) ; \widetilde{T}_{F S H}^{F o l l}(t), 2\right) .
$$

PGF $2 \alpha$ initiates the functional regression of the CL, and thereby the decrease in $\mathrm{P} 4$ levels. After a large time delay, $\mathrm{PGF} 2 \alpha$ synthesis is stimulated by elevated $\mathrm{P} 4$ levels above a specified threshold value. The PGF $2 \alpha$ level declines a couple of days after its rise, which is included as a delayed positive effect of $\mathrm{P} 4$ on the decay of PGF $2 \alpha$,

$$
\frac{d}{d t} P G F 2 \alpha(t)=H_{14}^{+}\left(P_{4, \tau}\right)-H_{15}^{+}\left(P_{4, \tau}\right) \cdot P G F 2 \alpha(t) .
$$

The LH peak initiates growth of the CL with a specified delay. After reaching a certain size, the CL continues to grow on its own as long as PGF2 $\alpha$ is low. The CL starts to regress when PGF $2 \alpha$ levels rise above a threshold,

$$
\frac{d}{d t} C L(t)=H_{16}^{+}\left(L H_{\tau}\right)+H_{17}^{+}(C L)-H_{18}^{+}(P G F 2 \alpha) \cdot C L(t) .
$$

The production of $\mathrm{P} 4$ is assumed to be proportional to CL function, and the production of $\mathrm{E} 2$ and Inh is assumed to be proportional to follicular function,

$$
\begin{aligned}
\frac{d}{d t} P_{4}(t) & =c_{C L}^{P_{4}} \cdot C L(t)-c_{P_{4}} \cdot P_{4}(t), \\
\frac{d}{d t} E_{2}(t) & =c_{F o l l}^{E_{2}} \cdot \operatorname{Foll}(t)-c_{E_{2}} \cdot E_{2}(t), \\
\frac{d}{d t} \operatorname{Inh}(t) & =c_{\text {Foll }}^{\text {Inh }} \cdot \operatorname{Foll}(t)-c_{\text {Inh }} \cdot \operatorname{Inh}(t) .
\end{aligned}
$$

The parameters $c_{P_{4}}, c_{E_{2}}$ and $c_{I n h}$ denote the respective clearance rate constants.

Figure 2 gives an overview of all mechanisms described by the model equations. Detailed notations for the Hill functions, parameters, and equations are given in $\mathrm{A}, \mathrm{B}$, and $\mathrm{C}$ respectively. 


\subsection{Parameter identification and sensitivity analysis}

Parameter identification is a mathematical challenge on its own. Many of the parameters are not measurable, sometimes the range of values is known, and some are completely unknown. Under those circumstances, estimating all 54 parameters simultaneously is impossible. To obtain good initial guesses of the parameter values for the optimization procedure, we use a model decomposition approach and successively enlarge the set of estimated parameters.

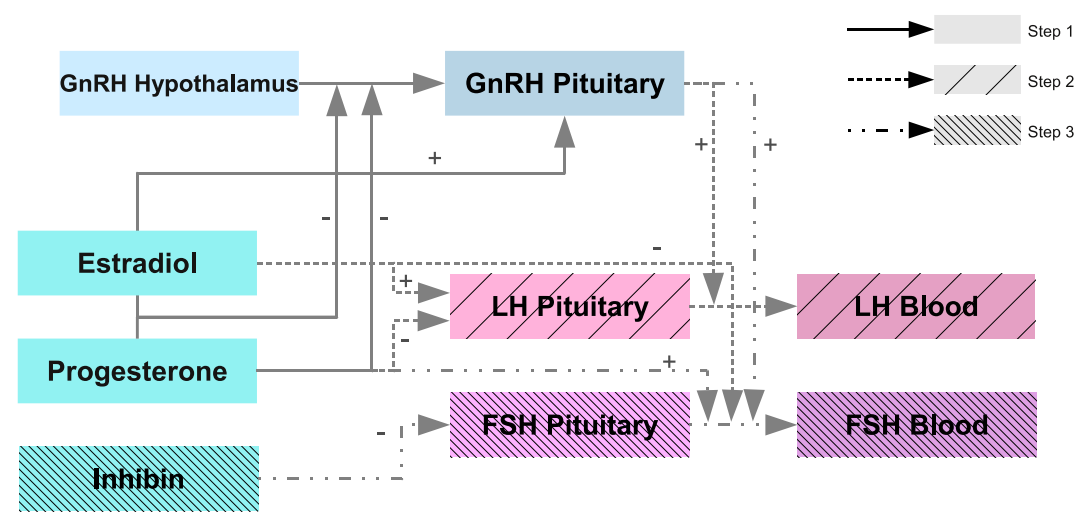

Figure 4: The first steps in generating good initial guesses for parameter optimization and enlarging the set of estimated parameters.

The first step in parameter estimation is to define input curves representing the development of Inh, P4, and E2 levels in the blood over time. Composition of these input curves is based on published data for endocrine profiles of cows with a normal estrous cycle, see for example [57],

$$
\begin{aligned}
E_{2}(t)= & 0.1111+0.44444 \exp \left(\frac{-(t+8)^{2}}{2}\right)+0.8889 \exp \left(\frac{-(t+1)^{2}}{3}\right) \\
& +0.4444 \exp \left(\frac{-(t-6)^{2}}{2}\right)+0.4444 \exp \left(\frac{-(t+29)^{2}}{2}\right), \\
P_{4}(t)= & \exp \left(\frac{-(t-9.5)^{2}}{30}\right)+\exp \left(\frac{-(t+11.5)^{2}}{30}\right), \\
\operatorname{Inh}(t)= & 0.1538+0.6154 \exp \left(\frac{-(t+8)^{2}}{2}\right)+0.8462 \exp \left(\frac{-(t+1)^{2}}{2}\right) \\
& +0.6154 \exp \left(\frac{-(t-6)^{2}}{2}\right)+0.6154 \exp \left(\frac{-(t+29)^{2}}{2}\right) .
\end{aligned}
$$

Moreover, we use the data for FSH, LH and GnRH as listed in Table 1. These are "hand-made" data chosen in such a way that the data points cover the qualitative behavior of the hormones as described in the literature. Therefore, we refer to these data as artificial data. They are normalized to be between zero and one in order to simplify parameter identification. However, as soon as we want to use measurement data with certain dimensions, the model components can be scaled easily. Note that the data points are chosen such that the LH peak occurs on day zero. 
Table 1: Artificial data values.

\begin{tabular}{lccc}
\hline day & LH & GnRH & FSH \\
\hline-10 & 0.1053 & 0.0053 & 1.0000 \\
-9 & 0.1105 & 0.0105 & 0.7449 \\
-8 & 0.1137 & 0.0137 & 0.3375 \\
-7 & 0.1189 & 0.0189 & 0.1492 \\
-6 & 0.1232 & 0.0232 & 0.1492 \\
-5 & 0.1253 & 0.0253 & 0.3375 \\
-4 & 0.1263 & 0.0263 & 0.7449 \\
-3 & 0.1368 & 0.0368 & 1.0000 \\
-2 & 0.1579 & 0.1079 & 0.7449 \\
-1 & 0.2632 & 0.2632 & 0.3375 \\
0 & 1.0000 & 1.0000 & 0.1492 \\
1 & 0.2632 & 0.2632 & 0.1492 \\
2 & 0.1579 & 0.1079 & 0.3375 \\
3 & 0.1368 & 0.0368 & 0.7449 \\
4 & 0.1263 & 0.0263 & 1.0000 \\
5 & 0.1253 & 0.0253 & 0.7449 \\
6 & 0.1232 & 0.0232 & 0.3375 \\
7 & 0.1189 & 0.0189 & 0.1492 \\
8 & 0.1137 & 0.0137 & 0.1492 \\
9 & 0.1105 & 0.0105 & 0.3375 \\
10 & 0.1053 & 0.0053 & 0.7449 \\
\hline
\end{tabular}

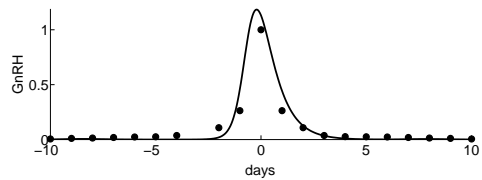

(a) $\mathrm{GnRH}$

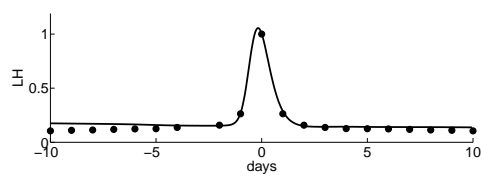

(c) $\mathrm{LH}$

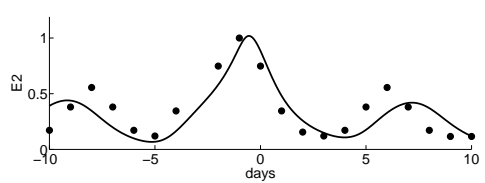

(e) E2

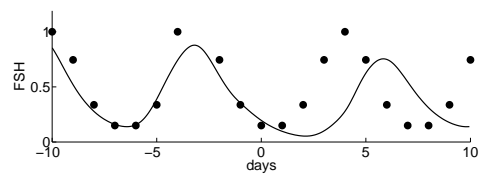

(b) FSH

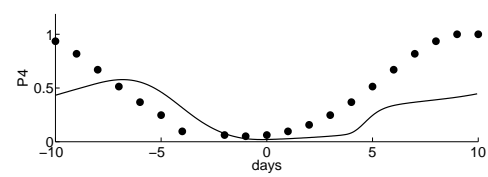

(d) P4

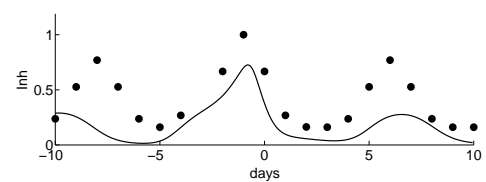

(f) Inh

Figure 5: Simulated curves of the closed model together with the artificial data points used for parameter optimization. Day zero corresponds to the day of LH peak. 


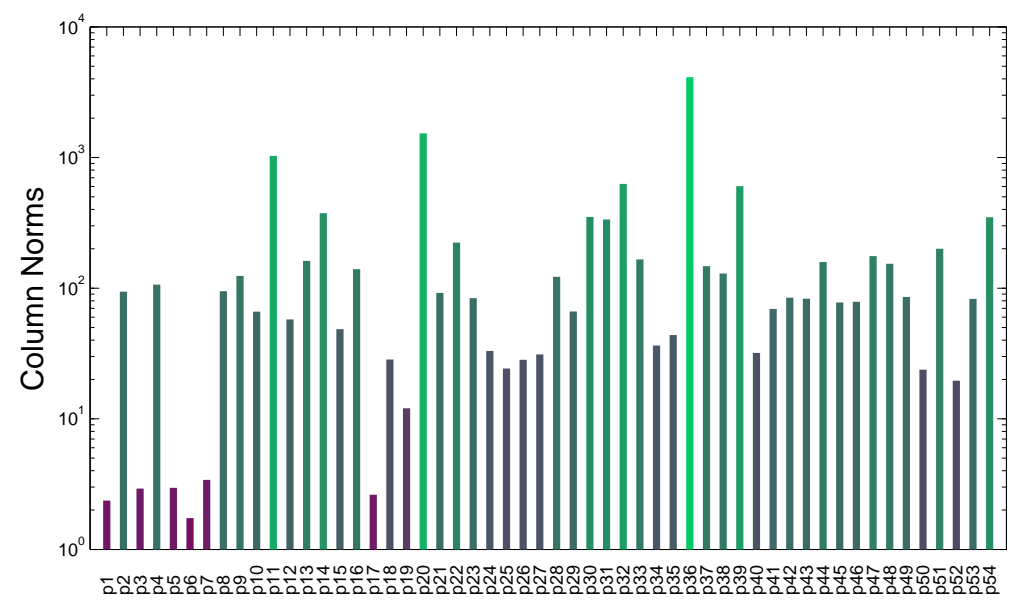

Figure 6: The column norms of the sensitivity matrix.

Following the approach in [34], we first take a small part of the model: the influence of P4 and E2 on GnRH. For this purpose, P4 and E2 are replaced by the corresponding input curves, and a subset of 10 parameters is optimized such that the simulated GnRH profile fits to the data values from Table 1. Thereafter, we consider the influence of $\mathrm{P} 4, \mathrm{E} 2$, and $\mathrm{GnRH}$ on $\mathrm{LH}$, and optimize 8 more parameters to obtain a good fit for the LH blood level. Subsequently, Inh is also replaced by its input curve, and 9 additional parameters are now estimated such that the resulting FSH blood profile fits our artificial data. These first steps are visualized in Figure 4.

Afterwards, the profiles of follicular function, PGF2 $\alpha$ and CL function are fitted to be in line with empirical knowledge. Finally, the input curves for P4, E2, and Inh are replaced by their original ODE/DDE description to obtain a closed network. The number of estimated parameters increases to 54 for the complete model. To estimate the remaining parameters, we generate artificial data for E2, P4, and Inh by evaluating the input functions at 21 days with $t=\{-10,-9, \ldots, 10\}$. An overview of the parameters is given in B.

Parameter estimation is done subsequently while generating the components of the model and enlarging the set of parameters. A parameter value obtained by the optimization procedure can be overwritten throughout the modeling process; the previous value then serves as starting value for the optimization procedure in the next modelling step. The final parameter values are listed in Table 2, and the corresponding simulation results are illustrated in Figure 5.

Throughout the model development, parameter identification is performed with the software package NLSCON [53], which has been developed and improved at the Zuse Institute over many years $[52,16]$. This program takes into account parameter sensitivities and linear dependencies, and it includes a number of optimization methods such as, for example, affine covariant Gauss-Newton methods [15].

Figures 6 and 7 illustrate the results of a sensitivity analysis for the complete model. The column norms of the sensitivity matrix contain the information 


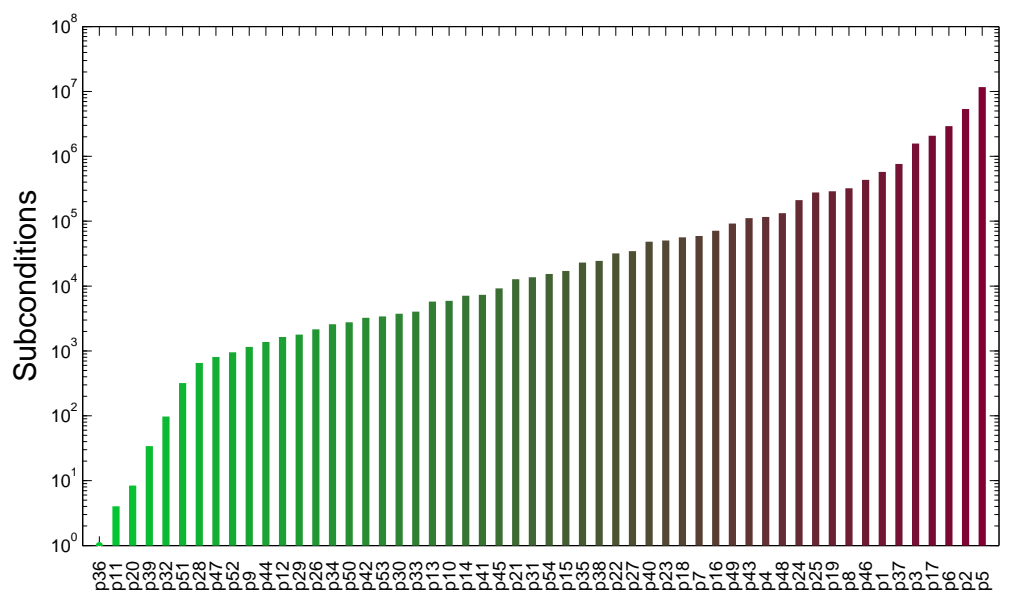

Figure 7: The subconditions of the parameters.

about the (normalized) sensitivities of the solution components with respect to the parameters at the artificial data points. A reordering of the parameters according to growing subcondition tells us which parameters can be estimated together. The predictability of parameter values decreases with increasing subcondition. It turns out that among the four most sensitive and best predictable parameters, there are three delays. This is not surprising since the delays have a large influence on the cycle length.

\section{Simulation results}

The figures in this section show the computed dynamics of follicle and CL development and accompanying fluctuations in hormone levels over consecutive cycles. The simulation results show that the current set of model parameters generates curves consistent with empirical knowledge for cows with a normal estrous cycle with three follicular waves. Notice that the model generates consecutive cycles that are not entirely identical, but that vary slightly in patterns and peak heights between cycles. Small differences in model output at the end of a cycle result in a different starting point of the next cycle, which leads to variation between the curves. This variation in hormone levels between cycles could well resemble variation within a cow over consecutive cycles. Each estrous cycle contains three waves of follicular growth (Figure 8). The CL starts to grow a few days after ovulation and is large during the first two follicular waves, which suppresses follicle growth. As the follicles grow, Inh increases and thus FSH decreases. Therefore, the support for the growth of the follicles declines, while the negative effect of $\mathrm{P} 4$ is still in place, leading to the decline of these follicles. After regression of the CL, the dominant follicle of the third follicular wave can continue to grow, leading to ovulation, which causes a sharp decline in follicular function.

The pattern of serum E2 levels is a result of follicular function (Figures 8 and 9). The third wave of follicular growth takes place when $\mathrm{P} 4$ levels are 


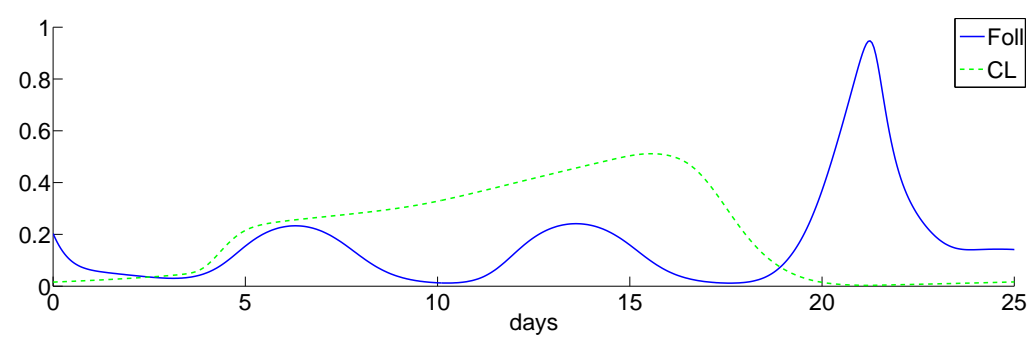

(a)

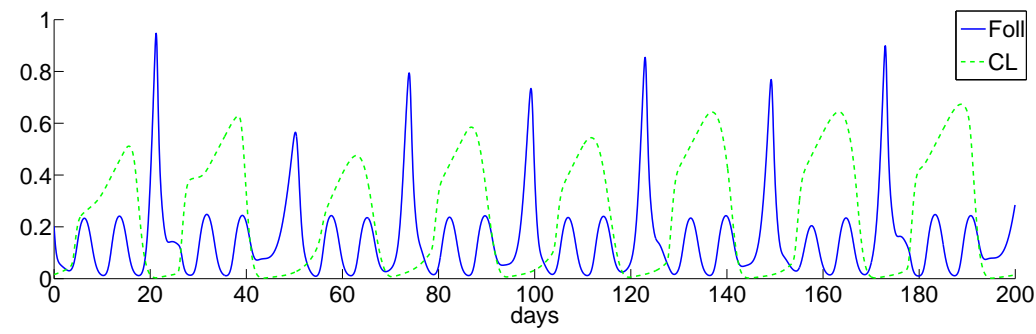

(b)

Figure 8: Output curves of follicular function (Foll) and CL function (CL) over time for one cycle (a) and in consecutive cycles (b).
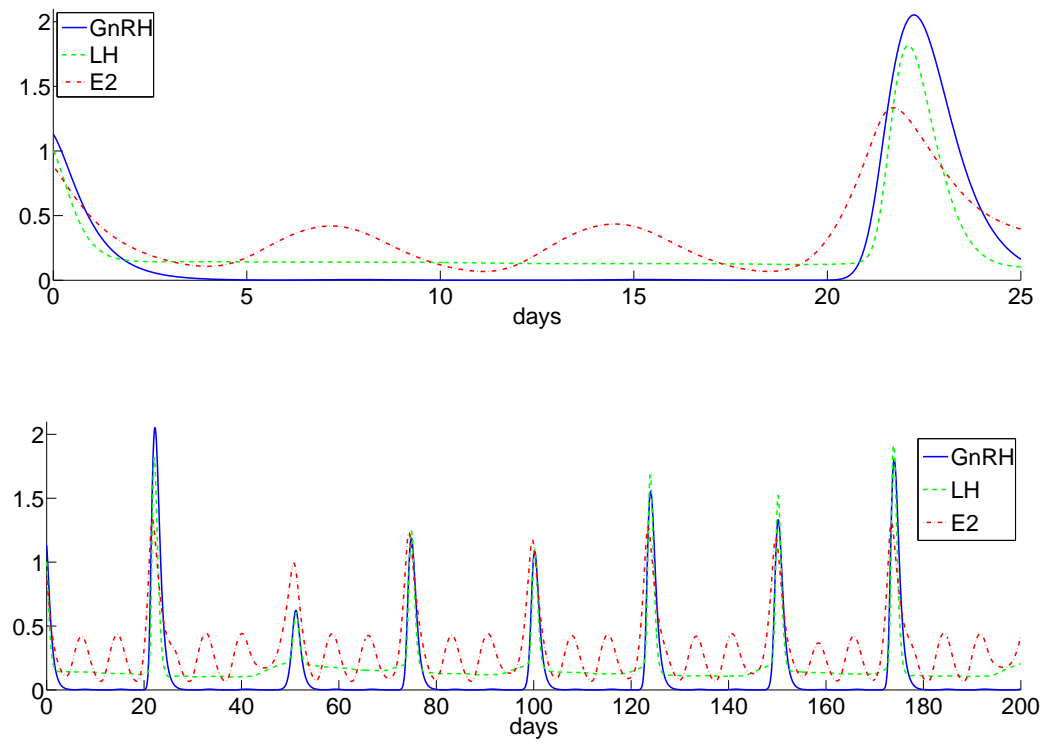

Figure 9: Output curves of serum concentrations of E2 and LH, and portal concentration of GnRH over time for one cycle (a) and in consecutive cycles (b). 


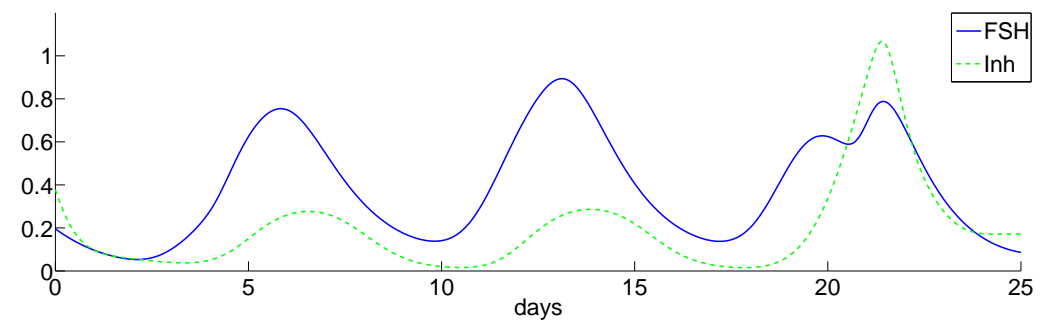

(a)

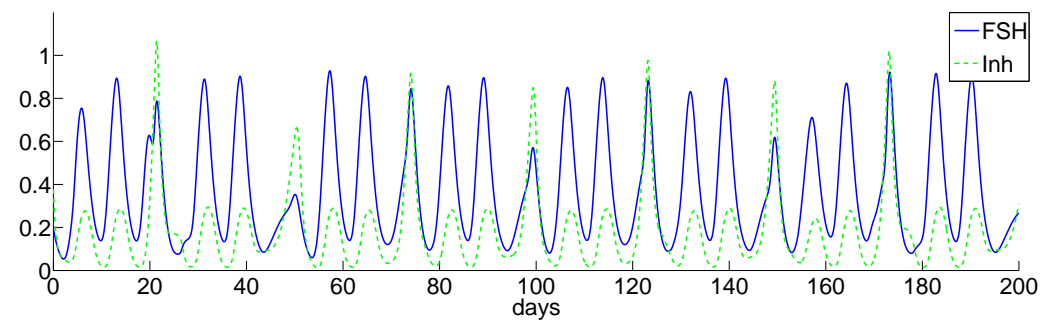

(b)

Figure 10: Output curves of serum concentrations of Inh and FSH over time for one cycle (a) and in consecutive cycles (b).

low, resulting in increased E2 levels. These increased E2 levels induce a steep GnRH and LH surge, which is the trigger for ovulation. Notice that the height of the GnRH surge is determined by the E2 peak level. During the remaining cycle, GnRH and LH levels are low, representing the lower pulse frequency and amplitude compared to the surge.

Increased FSH levels induce the growth of a follicular wave and thereby the start of Inh increase, but FSH is suppressed when Inh levels are above a certain level (Figure 10). Notice that FSH peak levels in the third wave of the cycle differ in consecutive cycles because of corresponding differences in height of the GnRH surge (Figures 9 and 10). When Inh has declined due to follicular regression, FSH increases again and induces the next follicular wave. Because follicular growth is modeled in three waves, also Inh levels rise in three waves in a cycle.

P4 serum levels are proportional to CL function. P4 concentration is small during the first days of the cycle and rises when the CL starts to grow (Figure 8). Notice that a lower LH peak height results in a less steep P4 increase and lower levels of P4 in the following cycle (Figures 9 and 11). Increased P4 levels induce a rise in PGF2 $\alpha$ after a couple of days, which causes CL regression and declining $\mathrm{P} 4$. 


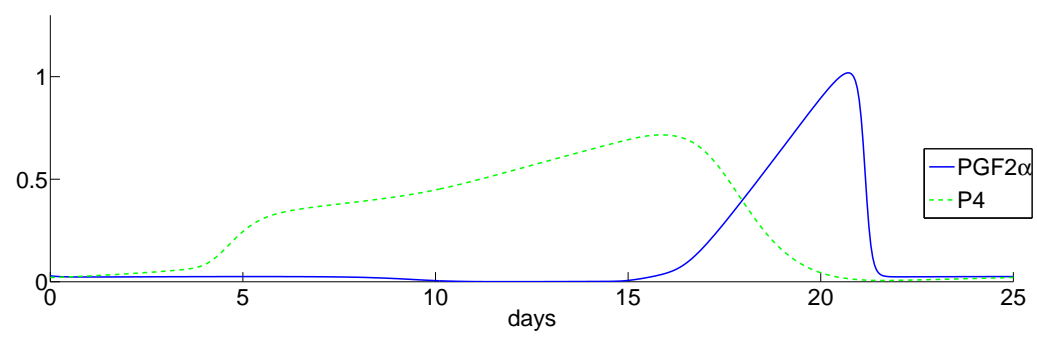

(a)

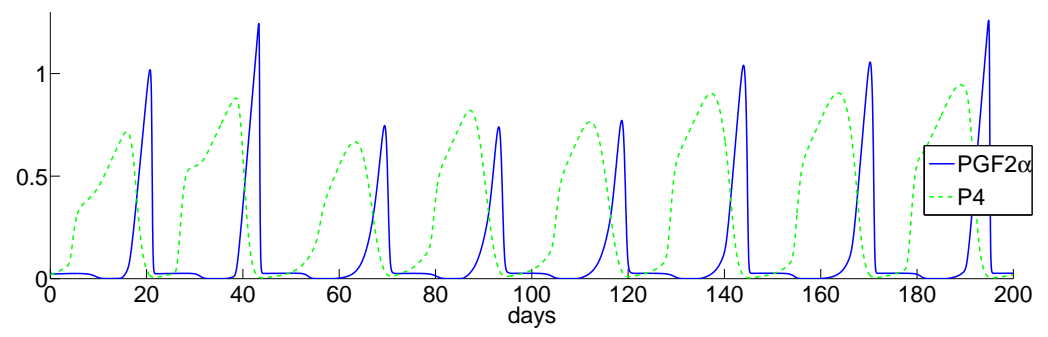

(b)

Figure 11: Output curves of serum concentrations of P4 and PGF2 $\alpha$ over time for one cycle (a) and in consecutive cycles (b).

\section{Discussion and Outlook}

The current mathematical model describes the interaction between a number of key physiological processes of the bovine estrous cycle. The model is able to simulate the dynamics of follicle and CL growth and development, as well as the associated hormone level changes in consecutive cycles. The current model comprises 12 equations and 54 parameters. The estrous cycles generated by the model are not entirely identical and could well resemble variations within a cow over consecutive cycles.

Although the current model is based on artificial data describing the mechanisms of an idealized cow, its fitting to measurement data of an individual cow is in principle possible and would represent the next step in the modeling approach. Because empirical data are usually noisy, parameter optimization must then also take into account measurement errors.

In future work, we want to use this model to determine the level of control exerted by various system components on the functioning of the system. Examples of such model applications are to explore the mechanisms that influence the pattern of follicular waves, or to study hormone patterns associated with subfertility. The model can serve as a basis for more elaborate models and simulations, with the ability to study effects of external manipulations and genetic differences. Possible extensions of the model could be in the field of energy metabolism, stress, disease, and factors affecting the expression of estrous behavior. There are relationships between regulation of the estrous cycle and 
energy balance, which can cause fertility problems in high producing dairy cows in negative energy balance (for reviews see [20,62]). Changes in reproductive performance that are associated with high milk production may in part be explained by elevated $\mathrm{P} 4$ and E2 clearance rates, as described in the physiological model of [79]. In this physiological model, clearance rates of hormones by the liver of cows with high milk production are increased as a result of elevated feed intake, leading to an increased liver blood flow and metabolic activity. With a similar level of hormone production, circulating hormone levels would thus be lower. Lameness, an example of a stress inducing condition, was found to inhibit the LH surge and ovulation, whereas incidence of estrous behavior (although with less intensity) was not reduced. These observations suggest that stress, caused by lameness, reduces P4 exposure before estrus and/or E2 production by the dominant follicle [21, 78]. Further, a normal endocrinological cycle is prerequisite for appropriate expression of estrous behavior. The relationships found between P4, E2 and intensity of estrous behavior show that hormones involved in regulation of the estrous cycle also affect the expression of estrous behavior $[42,63]$. These and other findings and hypotheses about regulation of the bovine estrous cycle could be translated into mathematical equations or modified parameterization and incorporated in the current model.

\section{Acknowledgements}

The authors would like to thank Dr B. Beerda, Prof Dr B. Kemp and Prof Dr M. Smits for their helpful comments on the manuscript. These results are obtained through IP/OP: Systems Biology, financially supported by the Dutch Ministry of Agriculture, Nature and Food Quality (BAS no. 4434660700). S. Röblitz and C. Stötzel have been supported by the DFG Research Center MATHEON "Mathematics for Key Technologies" in Berlin. 


\section{A List of Hill functions}

The Hill functions listed below are the full notations of the Hill functions mentioned in Section 3.2 and represent the mechanisms shown in Figure 2.

$$
\begin{aligned}
& H_{1}^{-}\left(P_{4} \& E_{2}\right):=m_{P_{4} \& E_{2}} \cdot\left(h^{-}\left(P_{4}(t) ; T_{P_{4}}^{G n R H, 1}, 2\right)+h^{-}\left(E_{2}(t), T_{E_{2}}^{G n R H, 1}, 2\right)\right. \\
& \left.-h^{-}\left(P_{4}(t) ; T_{P_{4}}^{G n R H, 1}, 2\right) \cdot h^{-}\left(E_{2}(t), T_{E_{2}}^{G n R H, 1}, 2\right)\right) \\
& H_{2}^{-}\left(P_{4}\right):=m_{P_{4}}^{G n R H, 2} \cdot h^{-}\left(P_{4}(t), T_{P_{4}}^{G n R H, 2}, 2\right) \\
& H_{3}^{+}\left(E_{2}\right):=m_{E_{2}}^{G n R H, 2} \cdot h^{+}\left(E_{2}(t), T_{E_{2}}^{G n R H, 2}, 5\right) \\
& H_{4}^{-}\left(I n h_{\tau}\right):=m_{I n h}^{F S H} \cdot h^{-}\left(\operatorname{Inh}\left(t-\tau_{I n h}\right), T_{I n h}^{F S H}, 2\right) \\
& H_{5}^{+}\left(P_{4}\right):=m_{P_{4}}^{F S H} \cdot h^{+}\left(P_{4}(t) ; T_{P_{4}}^{F S H}, 2\right) \\
& H_{6}^{-}\left(E_{2}\right):=m_{E_{2}}^{F S H} \cdot h^{-}\left(E_{2}(t) ; T_{E_{2}}^{F S H}, 2\right) \\
& H_{7}^{+}\left(G n R H_{P i t}\right):=m_{G n R H}^{F S H} \cdot h^{-}\left(G n R H_{P i t}(t) ; T_{G n R H}^{F S H}, 1\right) \\
& H_{8}^{+}\left(E_{2}\right):=m_{E_{2}}^{L H} \cdot h^{+}\left(E_{2}(t) ; T_{E_{2}}^{L H}, 2\right) \\
& H_{9}^{-}\left(P_{4}\right):=m_{P_{4}}^{L H} \cdot h^{-}\left(P_{4}(t) ; T_{P_{4}}^{L H}, 2\right) \\
& H_{10}^{+}\left(G n R H_{P i t}\right):=m_{G n R H}^{L H} \cdot h^{+}\left(G n R H_{P i t}(t) ; T_{G n R H}^{L H}, 2\right) \\
& H_{11}^{+}(F S H):=m_{F S H}^{F o l l} \cdot h^{+}\left(F S H_{\text {Blood }}(t) ; \widetilde{T}_{F S H}^{F o l l}(t), 2\right), \\
& \widetilde{T}_{F S H}^{\text {Foll }}(t):=T_{F S H}^{\text {Foll }} \cdot h^{-}\left(\text {Foll }(t) ; T_{\text {Foll }}^{F S H}, 1\right) \\
& H_{12}^{+}\left(P_{4}\right):=m_{P_{4}}^{\text {Foll }} \cdot h^{+}\left(P_{4}(t) ; T_{P_{4}}^{\text {Foll }}, 2\right) \\
& H_{13}^{+}(L H):=m_{L H}^{\text {Foll }} \cdot h^{-}\left(L H_{\text {Blood }}(t) ; T_{L H}^{\text {Foll }}, 2\right) \\
& H_{14}^{+}\left(P_{4, \tau}\right):=m_{P_{4}}^{P G F 2 \alpha, 1} \cdot h^{+}\left(P_{4}\left(t-\tau_{P_{4}, 1}\right), T_{P_{4}}^{P G F 2 \alpha}, 2\right) \\
& H_{15}^{+}\left(P_{4, \tau}\right):=m_{P_{4}}^{P G F 2 \alpha, 2} \cdot h^{+}\left(P_{4}\left(t-\tau_{P_{4}, 2}\right), T_{P_{4}}^{P G F 2 \alpha}, 10\right) \\
& H_{16}^{+}\left(L H_{\tau}\right):=m_{L H}^{C L} \cdot h^{+}\left(L H_{\text {Blood }}\left(t-\tau_{L H}\right) ; T_{L H}^{C L}, 2\right) \\
& H_{17}^{+}(C L):=m_{C L}^{C L} \cdot h^{+}\left(C L(t) ; T_{C L}^{C L}, 2\right) \\
& H_{18}^{+}(P G F 2 \alpha):=m_{P G F 2 \alpha}^{C L} \cdot h^{+}\left(P G F 2 \alpha(t) ; T_{P G F 2 \alpha}^{C L}, 1\right)
\end{aligned}
$$




\section{B List of parameters}

In our model, [.] stands for the unit of the substance, usually a concentration, and can be specified from measurements. Typical units are $[\mathrm{FSH}]=[\mathrm{LH}]=\mathrm{IU} / \mathrm{l}$, $[\mathrm{P} 4]=\mathrm{ng} / \mathrm{ml}$, and $[\mathrm{E} 2]=\mathrm{pg} / \mathrm{ml}$. t denotes "time"; in our model [t] stands for "days".

Table 2: List of parameters.

\begin{tabular}{|c|c|c|c|c|}
\hline No. & Symbol & Value & Quantity & Explanation \\
\hline 1 & $G n R H_{\text {Hypo }}^{\max }$ & 20 & {$\left[\mathrm{GnRH}_{\mathrm{Hypo}}\right]$} & $\begin{array}{l}\text { maximum value for GnRH in the hy- } \\
\text { pothalamus }\end{array}$ \\
\hline 2 & $c_{G n R H, 1}$ & 4.657 & $\frac{\left[\mathrm{GnRH}_{\mathrm{Hypo}}\right]}{[\mathrm{t}]}$ & $\begin{array}{l}\text { synthesis rate constant of } \mathrm{GnRH} \text { in the } \\
\text { hypothalamus }\end{array}$ \\
\hline 3 & $m_{P_{4} \& E_{2}}$ & 1.464 & $\frac{\left[\mathrm{GnRH}_{\mathrm{Hypo}}\right]}{[\mathrm{t}]}$ & $\begin{array}{l}\text { maximum part of } \mathrm{GnRH} \text { synthesis rate } \\
\text { constant inhibited by } \mathrm{E} 2 \text { and } \mathrm{P} 4\end{array}$ \\
\hline 4 & $T_{E_{2}}^{G n R H, 1}$ & 0.1433 & {$[\mathrm{E} 2]$} & $\begin{array}{l}\text { threshold of } \mathrm{E} 2 \text { to suppress GnRH re- } \\
\text { lease }\end{array}$ \\
\hline 5 & $T_{P_{4}}^{G n R H, 1}$ & 0.0294 & {$[\mathrm{P} 4]$} & $\begin{array}{l}\text { threshold of } \mathrm{P} 4 \text { to allow } \mathrm{E} 2 \text { suppression } \\
\text { of GnRH release }\end{array}$ \\
\hline 6 & $m_{P_{4}}^{G n R H, 2}$ & 1.503 & $1 /[\mathrm{t}]$ & $\begin{array}{l}\text { maximum part of } \mathrm{GnRH} \text { synthesis rate } \\
\text { constant inhibited by } \mathrm{P} 4\end{array}$ \\
\hline 7 & $T_{P_{4}}^{G n R H, 2}$ & 0.0309 & {$[\mathrm{P} 4]$} & $\begin{array}{l}\text { threshold of } \mathrm{P} 4 \text { to inhibit GnRH release } \\
\text { directly }\end{array}$ \\
\hline 8 & $m_{E_{2}}^{G n R H, 2}$ & 1.5 & $\frac{\left[\mathrm{GnRH}_{\mathrm{Pit}}\right]}{\left[\mathrm{GnRH}_{\mathrm{Hypo}}\right]}$ & $\begin{array}{l}\text { maximum scaling of pituitary sensitiv- } \\
\text { ity for GnRH }\end{array}$ \\
\hline 9 & $T_{E_{2}}^{G n R H, 2}$ & 1.276 & {$[\mathrm{E} 2]$} & $\begin{array}{l}\text { threshold of E2 to increase pituitary } \\
\text { sensitivity for GnRH }\end{array}$ \\
\hline 10 & $c_{G n R H, 2}$ & 1.299 & $1 /[\mathrm{t}]$ & $\begin{array}{l}\text { GnRH clearance rate constant in the pi- } \\
\text { tuitary }\end{array}$ \\
\hline 11 & $\tau_{\text {Inh }}$ & 1.5 & {$[\mathrm{t}]$} & delay \\
\hline 12 & $m_{I n h}^{F S H}$ & 1 & {$[\mathrm{FSH}] /[\mathrm{t}]$} & $\begin{array}{l}\text { maximum FSH synthesis rate in the pi- } \\
\text { tuitary in the absence of Inh }\end{array}$ \\
\hline 13 & $T_{I n h}^{F S H}$ & 0.06 & {$[\operatorname{Inh}]$} & $\begin{array}{l}\text { threshold of Inh for inhibition of FSH } \\
\text { synthesis }\end{array}$ \\
\hline 14 & $m_{P_{4}}^{F S H}$ & 2 & $1 /[\mathrm{t}]$ & $\begin{array}{l}\text { maximum part of FSH release rate that } \\
\text { is stimulated by } \mathrm{P} 4\end{array}$ \\
\hline 15 & $T_{P_{4}}^{F S H}$ & 0.0966 & {$[\mathrm{P} 4]$} & $\begin{array}{l}\text { threshold of } \mathrm{P} 4 \text { to stimulate } \mathrm{FSH} \text { re- } \\
\text { lease }\end{array}$ \\
\hline 16 & $m_{E_{2}}^{F S H}$ & 0.3 & $1 /[\mathrm{t}]$ & $\begin{array}{l}\text { maximum part of FSH release rate that } \\
\text { is inhibited by E2 }\end{array}$ \\
\hline 17 & $T_{E_{2}}^{F S H}$ & 2.846 & {$[\mathrm{E} 2]$} & threshold of E2 to inhibit FSH release \\
\hline 18 & $m_{G n R H}^{F^{2} S H}$ & 3 & $1 /[\mathrm{t}]$ & $\begin{array}{l}\text { maximum part of FSH release rate that } \\
\text { is stimulated by GnRH }\end{array}$ \\
\hline 19 & $T_{G n R H}^{F S H}$ & 0.4 & {$[\mathrm{GnRH}]$} & $\begin{array}{l}\text { threshold of } \mathrm{GnRH} \text { to stimulate } \mathrm{FSH} \\
\text { release }\end{array}$ \\
\hline 20 & $S H$ & 0.8 & $1 /[\mathrm{t}]$ & FSH clearance rate constant \\
\hline
\end{tabular}

Continued on next page... 
Table 2 - continued from previous page

\begin{tabular}{|c|c|c|c|c|}
\hline No. & Symbol & Value & Quantity & Explanation \\
\hline 21 & $m_{E_{2}}^{L H}$ & 1.5 & {$[\mathrm{LH}] /[\mathrm{t}]$} & $\begin{array}{l}\text { maximum part of LH synthesis that is } \\
\text { stimulated by E2 }\end{array}$ \\
\hline 22 & $T_{E_{2}}^{L H}$ & 0.1 & {$[\mathrm{E} 2]$} & $\begin{array}{l}\text { threshold of E2 to stimulate LH synthe- } \\
\text { sis }\end{array}$ \\
\hline 23 & $m_{P_{4}}^{L H}$ & 4.5 & {$[\mathrm{LH}] /[\mathrm{t}]$} & $\begin{array}{l}\text { maximum part of LH synthesis that is } \\
\text { inhibited by } \mathrm{P} 4\end{array}$ \\
\hline 24 & $T_{P_{4}}^{L H}$ & 0.0322 & {$[\mathrm{P} 4]$} & threshold of P4 to inhibit LH synthesis \\
\hline 25 & $m_{G n R H}^{L}$ & 4 & $1 /[\mathrm{t}]$ & $\begin{array}{l}\text { maximum part of } \mathrm{LH} \text { release rate that } \\
\text { is stimulated by } \mathrm{GnRH}\end{array}$ \\
\hline 26 & $T_{G n R H}^{L H}$ & 4 & {$[\mathrm{GnRH}]$} & $\begin{array}{l}\text { threshold of GnRH to stimulate LH re- } \\
\text { lease }\end{array}$ \\
\hline 27 & $b_{L H}$ & 0.05 & $1 /[\mathrm{t}]$ & basal LH release rate constant \\
\hline 28 & $c_{L H}$ & 11 & $1 /[\mathrm{t}]$ & LH clearance rate constant \\
\hline 29 & $m_{F S H}^{F o l l}$ & 0.8 & {$[$ Foll $] /[\mathrm{t}]$} & $\begin{array}{l}\text { maximum increase of follicular function } \\
\text { stimulated by FSH }\end{array}$ \\
\hline 30 & $T_{F S H}^{F o l l}$ & 0.8 & {$[\mathrm{FSH}]$} & $\begin{array}{l}\text { threshold of FSH to stimulate follicular } \\
\text { function }\end{array}$ \\
\hline 31 & $T_{\text {Foll }}^{F S H}$ & 0.3 & {$[$ Foll $]$} & $\begin{array}{l}\text { threshold of follicular function to down- } \\
\text { scale FSH threshold }\end{array}$ \\
\hline 32 & $m_{P_{4}}^{\text {Foll }}$ & 2.5 & $1 /[\mathrm{t}]$ & $\begin{array}{l}\text { maximum part of follicular decay stim- } \\
\text { ulated by P4 }\end{array}$ \\
\hline 33 & $T_{P_{4}}^{\text {Foll }}$ & 0.1127 & {$[\mathrm{P} 4]$} & $\begin{array}{l}\text { threshold of } \mathrm{P} 4 \text { to stimulate decrease of } \\
\text { follicular function }\end{array}$ \\
\hline 34 & $m_{L H}^{\text {Foll }}$ & 2.8 & $1 /[\mathrm{t}]$ & $\begin{array}{l}\text { maximum part of follicular decay stim- } \\
\text { ulated by LH }\end{array}$ \\
\hline 35 & $T_{L H}^{\text {Foll }}$ & 0.525 & {$[\mathrm{LH}]$} & $\begin{array}{l}\text { threshold of LH to stimulate decrease } \\
\text { of follicular function }\end{array}$ \\
\hline 36 & $\tau_{P_{4}, 1}$ & 12 & {$[\mathrm{t}]$} & $\begin{array}{l}\text { delay of P4 until stimulating PGF } 2 \alpha \text { in- } \\
\text { crease }\end{array}$ \\
\hline 37 & $m_{P_{4}}^{P G F 2 \alpha, 1}$ & 0.3 & {$[\mathrm{PGF} 2 \alpha] /[\mathrm{t}]$} & maximum growth rate of PGF $2 \alpha$ \\
\hline 38 & $T_{P_{4}}^{P G F 2 \alpha, 1}$ & 0.1672 & {$[\mathrm{P} 4]$} & $\begin{array}{l}\text { threshold of P4 to stimulate PGF } 2 \alpha \text { in- } \\
\text { crease }\end{array}$ \\
\hline 39 & $\tau_{P_{4}, 2}$ & 17 & {$[\mathrm{t}]$} & $\begin{array}{l}\text { delay of P4 until stimulating PGF2 } \alpha \\
\text { decrease }\end{array}$ \\
\hline 40 & $m_{P_{4}}^{P G F 2 \alpha, 2}$ & 11 & {$[\mathrm{PGF} 2 \alpha] /[\mathrm{t}]$} & maximum decay rate of $\mathrm{PGF} 2 \alpha$ \\
\hline 41 & $T_{P_{4}}^{P G F 2 \alpha, 1}$ & 0.0966 & {$[\mathrm{P} 4]$} & $\begin{array}{l}\text { threshold of P4 to stimulate PGF } 2 \alpha \text { de- } \\
\text { crease }\end{array}$ \\
\hline 42 & $\tau_{L H}$ & 4.5 & [t] & delay of $\mathrm{LH}$ in $\mathrm{CL}$ \\
\hline 43 & $m_{L H}^{C L}$ & 0.334 & {$[\mathrm{CL}] /[\mathrm{t}]$} & $\begin{array}{l}\text { maximum increase of CL stimulated by } \\
\text { LH }\end{array}$ \\
\hline 44 & $T_{L H}^{C L}$ & 1.2 & {$[\mathrm{LH}]$} & $\begin{array}{l}\text { threshold of LH to stimulate CL in- } \\
\text { crease }\end{array}$ \\
\hline 45 & $m_{C L}^{C L}$ & 0.0334 & {$[\mathrm{CL}] /[\mathrm{t}]$} & $\begin{array}{l}\text { maximum increase of CL stimulated by } \\
\text { itself }\end{array}$ \\
\hline
\end{tabular}


Table 2 - continued from previous page

\begin{tabular}{|c|c|c|c|c|}
\hline No. & Symbol & Value & Quantity & Explanation \\
\hline 46 & $T_{C L}^{C L}$ & 0.0651 & {$[\mathrm{CL}]$} & threshold of CL to stimulate self-growth \\
\hline 47 & $m_{P G F 2 \alpha}^{C L}$ & 6.536 & $1 /[\mathrm{t}]$ & $\begin{array}{l}\text { maximum decrease of CL stimulated by } \\
\text { PGF } 2 \alpha\end{array}$ \\
\hline 48 & $T_{P G F 2 \alpha}^{C L}$ & 2 & {$[\mathrm{PGF} 2 \alpha]$} & $\begin{array}{l}\text { threshold of PGF } 2 \alpha \text { to initiate decrease } \\
\text { of CL }\end{array}$ \\
\hline 49 & $c_{C L}^{P_{4}}$ & 3.856 & $\frac{[\mathrm{P} 4] /[\mathrm{CL}]}{1 /[\mathrm{t}]}$ & $\begin{array}{l}\text { proportionality factor of CL in } \mathrm{P} 4 \text { in- } \\
\text { crease }\end{array}$ \\
\hline 50 & $c_{P_{4}}$ & 2.737 & $1 /[\mathrm{t}]$ & $\mathrm{P} 4$ clearance rate constant \\
\hline 51 & $c_{\text {Foll }}^{E_{2}}$ & 1.9 & $\frac{[\mathrm{E} 2] /[\mathrm{Foll}]}{1 /[\mathrm{t}]}$ & $\begin{array}{l}\text { proportionality factor of follicular func- } \\
\text { tion in E2 increase }\end{array}$ \\
\hline 52 & $c_{E_{2}}$ & 0.9 & $1 /[\mathrm{t}]$ & E2 clearance rate constant of \\
\hline 53 & $c_{\text {Foll }}^{I n h}$ & 4.8 & $\frac{[\operatorname{Inh}] /[\mathrm{Foll}]}{1 /[\mathrm{t}]}$ & $\begin{array}{l}\text { proportionality factor of delayed follic- } \\
\text { ular function in Inh increase }\end{array}$ \\
\hline 54 & $c_{\text {Inh }}$ & 4 & $1 /[\mathrm{t}]$ & Inh clearance rate constant \\
\hline
\end{tabular}

\section{List of equations}

\begin{tabular}{clc}
\hline no & component & initial value \\
\hline 1 & GnRH $_{\text {Pit }}$ & 1.598 \\
2 & GnRH $_{\text {Blood }}$ & 0.05003 \\
3 & FSH $_{\text {Pit }}$ & 0.3994 \\
4 & FSH $_{\text {Blood }}$ & 0.7996 \\
5 & LH $_{\text {Pit }}$ & 20.38 \\
6 & LH $_{\text {Blood }}$ & 0.1096 \\
7 & Foll & 0.3988 \\
8 & PGF $2 \alpha$ & 0.03992 \\
9 & CL & 0.9808 \\
10 & $P_{4}$ & 0.9995 \\
11 & $E_{2}$ & 0.009995 \\
12 & Inh & 0.1001 \\
\hline
\end{tabular}

Table 3: Initial values

The equations listed below are the full notations of the equations developed in Section 3.2. Parameters are denoted with $p$ and are numbered according to Table 2. Components numbering and initial values can be found in Table 3 . 


$$
\begin{aligned}
& \frac{d}{d t} y_{1}(t)=p_{2} \cdot\left(1-\frac{y_{1}(t)}{p_{1}}\right)-\left(p _ { 3 } \cdot \left(h^{-}\left(y_{10}(t) ; p_{5}, 2\right)+h^{-}\left(y_{11}(t) ; p_{4}, 2\right)\right.\right. \\
& \left.\left.-h^{-}\left(y_{10}(t) ; p_{5}, 2\right) \cdot h^{-}\left(y_{11}(t) ; p_{4}, 2\right)\right)-p_{6} \cdot h^{-}\left(y_{10}(t) ; p_{7}, 2\right)\right) \cdot y_{1}(t) \\
& \frac{d}{d t} y_{2}(t)=\left(p _ { 3 } \cdot \left(h^{-}\left(y_{10}(t) ; p_{5}, 2\right)+h^{-}\left(y_{11}(t), p_{4}, 2\right)\right.\right. \\
& \left.-h^{-}\left(y_{10}(t) ; p_{5}, 2\right) \cdot h^{-}\left(y_{11}(t) ; p_{4}, 2\right)\right) \\
& \left.+p_{6} \cdot h^{-}\left(y_{10}(t) ; p_{7}, 2\right)\right) \cdot y(1) \cdot p_{8} \cdot h^{+}\left(y_{11}(t) ; p_{9}, 5\right)-p_{10} \cdot y_{2}(t) \\
& \frac{d}{d t} y_{3}(t)=p_{12} \cdot h^{-}\left(y_{12}\left(t-p_{11}\right) ; p_{13}, 2\right)-\left(p_{14} \cdot h^{+}\left(y_{10}(t) ; p_{15}, 2\right)\right. \\
& \left.+p_{16} \cdot h^{-}\left(y_{11}(t) ; p_{17}, 2\right)+p_{18} \cdot h^{+}\left(y_{2}(t) ; p_{19}, 1\right)\right) \cdot y_{3}(t) \\
& \frac{d}{d t} y_{4}(t)=\left(p_{14} \cdot h^{+}\left(y_{10}(t) ; p_{15}, 2\right)+p_{16} \cdot h^{-}\left(y_{11}(t) ; p_{17}, 2\right)\right. \\
& \left.+p_{18} \cdot h^{+}\left(y_{2}(t) ; p_{19}, 1\right)\right) \cdot y_{3}(t)-p_{20} \cdot y_{4}(t) \\
& \frac{d}{d t} y_{5}(t)=p_{21} \cdot h^{+}\left(y_{11}(t) ; p_{22}, 2\right)+p_{23} \cdot h^{-}\left(y_{10}(t) ; p_{24}, 2\right) \\
& -\left(p_{27}+p_{25} \cdot h^{+}\left(y_{2}(t) ; p_{26}, 2\right)\right) \cdot y_{5}(t) \\
& \frac{d}{d t} y_{6}(t)=\left(p_{27}+p_{25} \cdot h^{+}\left(y_{2}(t) ; p_{26}, 2\right)\right) \cdot y_{5}(t)-p_{28} \cdot y_{6}(t) \\
& \frac{d}{d t} y_{7}(t)=p_{29} \cdot h^{+}\left(y_{4}(t) ; p_{30} \cdot h^{-}\left(y_{7}(t) ; p_{31}, 1\right), 2\right) \\
& -\left(p_{32} \cdot h^{+}\left(y_{10}(t) ; p_{33}, 2\right)+p_{34} \cdot h^{+}\left(y_{6}(t) ; p_{35}, 2\right)\right) \cdot y_{7}(t) \\
& \frac{d}{d t} y_{8}(t)=p_{37} \cdot h^{+}\left(y_{10}\left(t-p_{36}\right) ; p_{38}, 2\right)-p_{40} \cdot h^{+}\left(y_{10}\left(t-p_{39}\right) ; p_{41}, 10\right) \cdot y_{8}(t) \\
& \frac{d}{d t} y_{9}(t)=p_{43} \cdot h^{+}\left(y_{6}\left(t-p_{42}\right) ; p_{44}, 2\right)+p_{45} \cdot h^{+}\left(y_{9}(t) ; p_{46}, 2\right) \\
& -p_{47} \cdot h^{+}\left(y_{8}(t) ; p_{48}, 2\right) \cdot y_{9}(t) \\
& \frac{d}{d t} y_{10}(t)=p_{49} \cdot y_{9}(t)-p_{50} \cdot y_{10}(t) \\
& \frac{d}{d t} y_{11}(t)=p_{51} \cdot y_{7}(t)-p_{52} \cdot y_{11}(t) \\
& \frac{d}{d t} y_{12}(t)=p_{53} \cdot y_{7}(t)-p_{54} \cdot y_{12}(t)
\end{aligned}
$$




\section{References}

[1] T. J. Acosta, T. Ozawa, S. Kobayashi, K. Hayashi, M. Ohtani, W. D. Kraetzl, K. Sato, D. Schams, and A. Miyamoto. Periovulatory changes in the local release of vasoactive peptides, prostaglandin F $2 \alpha$, and steroid hormones from bovine mature follicles in vivo. Biol. Reprod., 63:1253-1261, 2000.

[2] T.J. Acosta. Studies of follicular vascularity associated with follicle selection and ovulation in cattle. J. Reprod. Dev., 53:39-44, 2007.

[3] G. P. Adams, R. Jaiswal, J. Singh, and P. Malhi. Progress in understanding ovarian follicular dynamics in cattle. Theriogenology, 69:72-80, 2008.

[4] G. P. Adams, R. L. Matteri, and O. J. Ginther. Effect of progesterone on ovarian follicles, emergence of follicular waves and circulating folliclestimulating hormone in heifers. J. Reprod. Fertil., 96:627-640, 1992.

[5] R. R. Araujo, O. J. Ginther, J. C. Ferreira, M. M. Palh ao, M. A. Beg , and M. C. Wiltbank. Role of follicular estradiol-17beta in timing of luteolysis in heifers. Biol. Reprod., 81:426-437, 2009.

[6] B. Bao and H. A. Garverick. Expression of steroidogenic enzyme and gonadotropin receptor genes in bovine follicles during ovarian follicular waves: A review. J. Anim. Sci., 76:1903-1921, 1998.

[7] M. A. Beg, D. R. Bergfelt, K. Kot, and O. J. Ginther. Follicle selection in cattle: Dynamics of follicular fluid factors during development of follicle dominance. Biol. Reprod., 66:120-126, 2002.

[8] E. G. M. Bergfeld, F. N. Kojima, A. S. Cupp, M. E. Wehrman, K. E. Peters, V. Mariscal, T. Sanchez, and J. E. Kinder. Changing dose of progesterone results in sudden changes in frequency of luteinizing hormone pulses and secretion of 17 $\beta$-estradiol in bovine females. Biol. Reprod., 54:546-553, 1996.

[9] B. Berisha and D. Schams. Ovarian function in ruminants. Domest. Anim. Endocrinol., 29:305-317, 2005.

[10] E. C. L. Bleach, R. G. Glencross, S. A. Feist, N. P. Groome, and P. G. Knight. Plasma inhibin A in heifers: Relationship with follicle dynamics, gonadotropins, and steroids during the estrous cycle and after treatment with bovine follicular fluid. Biol. Reprod., 64:743-752, 2001.

[11] H. M. T. Boer, R. F. Veerkamp, B. Beerda, and H. Woelders. Estrous behavior in dairy cows: identification of underlying mechanisms and gene functions. Animal, 4:446-453., 2010.

[12] J. R. Chenault, W. W. Thatcher, P. S. Kalra, R. M. Abrams, and C. J. Wilcox. Transitory changes in plasma progestins, estradiol, and luteinizing hormone approaching ovulation in the bovine. J. Dairy Sci., 58:709-717, 1975. 
[13] F. Clément, D. Monniaux, J.-C. Thalabard, and D. Claude. Contribution of a mathematical modelling approach to the understanding of the ovarian function. C. R. Biol., 325:473-485, 2002.

[14] L. C. Cruz, E. R. DoValle, and D. J. Kesler. Effect of prostaglandin F2 $\alpha$ and gonadotropin releasing hormone-induced luteinizing hormone releases on ovulation and corpus luteum function of beef cows. Anim. Reprod. Sci., 49:135-142, 1997.

[15] P. Deuflhard. Newton methods for nonlinear problems: affine invariance and adaptive algorithms. Number 35 in Springer Series in Computational Mathematics. Springer Verlag, Berlin, 2004.

[16] P. Deuflhard and U. Nowak. Efficient numerical simulation and identification of large chemical reaction systems. Ber. Bunsenges. Phys. Chem, 90:940-946, 1986.

[17] T. Díaz, M. Manzo, J. Trocóniz, N. Benacchio, and O. Verde. Plasma progesterone levels during the estrous cycle of Holstein and Brahman cows, Carora type and cross-bred heifers. Theriogenology, 26:419-432, 1986.

[18] S. J. Dieleman, M. M. Bevers, H. T. M. Van Tol, and A. H. Willemse. Peripheral plasma concentrations of oestradiol, progesterone, cortisol, LH and prolactin during the oestrous cycle in the cow, with emphasis on the peri-oestrous period. Anim. Reprod. Sci., 10:275-292, 1986.

[19] S. J. Dieleman and D. M. Blankenstein. Progesterone-synthesizing ability of preovulatory follicles of cows relative to the peak of LH. J. Reprod. Fertil., 75:609-615, 1985.

[20] M. G. Diskin, D. R. Mackey, J. F. Roche, and J. M. Sreenan. Effects of nutrition and metabolic status on circulating hormones and ovarian follicle development in cattle. Anim. Reprod. Sci., 78:345-370, 2003.

[21] H. Dobson, S.L. Walker, M. J. Morris, J. E. Routly, and R. F. Smith. Why is it getting more difficult to successfully artificially inseminate dairy cows? Animal, 2:1104-1111, 2008.

[22] R. M. dos Santos, M. D. Goissis, D. A. Fantini, C. M. Bertan, J. L. M. Vasconcelos, and M. Binelli. Elevated progesterone concentrations enhance prostaglandin F2 $\alpha$ synthesis in dairy cows. Anim. Reprod. Sci., 114:62-71, 2009.

[23] S. E. Echternkamp and W. Hansel. Concurrent changes in bovine plasma hormone levels prior to and during the first postpartum estrous cycle. $J$. Anim. Sci., 37:1362-1370, 1973.

[24] A. C. O. Evans, C. M. Komar, S. A. Wandji, and J. E. Fortune. Changes in androgen secretion and luteinizing hormone pulse amplitude are associated with the recruitment and growth of ovarian follicles during the luteal phase of the bovine estrous cycle. Biol. Reprod., 57:394-401, 1997. 
[25] J. K. Findlay, I. J. Clarke, and D. M. Robertson. Inhibin concentrations in ovarian and jugular venous plasma and the relationship of inhibin with follicle-stimulating hormone and luteinizing hormone during the ovine estrous cycle. Endocrinology, 126:528-535, 1990.

[26] J. E. Fortune. Ovarian follicular growth and development in mammals. Biol. Reprod., 50:225-232, 1994.

[27] O. J. Ginther, M. A. Beg, D. R. Bergfelt, F. X. Donadeu, and K. Kot. Follicle selection in monovular species. Biol. Reprod., 65:638-647, 2001b.

[28] O. J. Ginther, D. R. Bergfelt, M. A. Beg, and K. Kot. Follicle selection in cattle: Relationships among growth rate, diameter ranking, and capacity for dominance. Biol. Reprod., 65:345-350, 2001a.

[29] O. J. Ginther, D. R. Bergfelt, M. A. Beg, and K. Kot. Role of low circulating FSH concentrations in controlling the interval to emergence of the subsequent follicular wave in cattle. Reproduction, 124:475-482, 2002.

[30] R. G. Glencross, R. J. Esslemont, M. J. Bryant, and G. S. Pope. Relationships between the incidence of pre-ovulatory behaviour and the concentrations of oestradiol-17 $\beta$ and progesterone in bovine plasma. Appl. Anim. Ethol., 7:141-148, 1981.

[31] C. Glidewell-Kenney, L. A. Hurley, L. Pfaff, J. Weiss, J. E. Levine, and J. L. Jameson. Nonclassical estrogen receptor $\alpha$ signaling mediates negative feedback in the female mouse reproductive axis. Proc. Natl. Acad. Sci. U.S.A., 104:8173-8177, 2007.

[32] R. L. Goodman and E. Keith Inskeep. Neuroendocrine control of the ovine estrous cycle. In E. Knobil and J.D. Neill, editors, The physiology of reproduction, volume 2, chapter 44, pages 1929-1969. Raven Press, New York, 1 edition, 1988.

[33] N. Guglielmi and E. Hairer. Radar5, 2005. http://www.unige.ch/ wairer/software.html.

[34] L. A. Harris. Differential equation models for the hormonal regulation of the menstrual cycle. PhD thesis, North Carolina State University, 2001.

[35] K. Heinze, R. W. Keener, and A. R. Midgley. A mathematical model of luteinizing hormone release from ovine pituitary cells in perifusion. Am. J. Physiol. Endocrinol. Metab., 275:1061-1071, 1998.

[36] J. J. Ireland, M. Mihm, E. Austin, M. G. Diskin, and J. F. Roche. Historical perspective of turnover of dominant follicles during the bovine estrous cycle: Key concepts, studies, advancements, and terms. J. Dairy Sci., 83:16481658, 2000.

[37] L. N. Kanchev, H. Dobson, W. R. Ward, and R. J. Fitzpatrick. Concentration of steroids in bovine peripheral plasma during the oestrous cycle and the effect of betamethasone treatment. J. Reprod. Fertil., 48:341-345, 1976. 
[38] H. Kaneko, H. Kishi, G. Watanabe, K. Taya, S. Sasamoto, and H. Yoshihisa. Changes in plasma concentrations of immunoreactive inhibin, estradiol and FSH associated with follicular waves during the estrous cycle of the cow. J. Reprod. Dev., 41:311-320, 1995.

[39] S. Kawakami, T. Shida, M. Mutoh, H. Kohmoto, and T. Ohchi. Relation between luteal regression and so-called counter current mechanism in the cow: verification from PGF2 $\alpha$ concentrations in ovarian arterial, uterine venous and jugular venous blood following PGF2 $\alpha$ loading. J. Reprod. Dev., 41:219-223, 1995.

[40] J. Kotwica and G.L. Williams. Relationship of plasma testosterone concentrations to pituitary-ovarian hormone secretion during the bovine estrous cycle and the effects of testosterone propionate administered during luteal regression. Biol. Reprod., 27:790-801, 1982.

[41] E. A. Lane, V. Padmanabhan, J. F. Roche, and M. A. Crowe. Alterations in the ability of the bovine pituitary gland to secrete gonadotropins in vitro during the first follicle-stimulating hormone increase of the estrous cycle and in response to exogenous steroids. Domest. Anim. Endocrinol., 28:190-201, 2005.

[42] Z. C. Lyimo, M. Nielen, W. Ouweltjes, T. A. M. Kruip, and F. J. C. M. van Eerdenburg. Relationship among estradiol, cortisol and intensity of estrous behavior in dairy cattle. Theriogenology, 53:1783-1795, 2000.

[43] G. E. Mann and G. E. Lamming. Progesterone inhibition of the development of the luteolytic signal in cows. J. Reprod. Fertil., 104:1-5, 1995.

[44] G. E. Mann and G. E. Lamming. Relationship between maternal endocrine environment, early embryo development and inhibition of the luteolytic mechanism in cows. Reproduction, 121:175-180, 2001.

[45] G. E. Mann, G. E. Lamming, and J. H. Payne. Role of early luteal phase progesterone in control of the timing of the luteolytic signal in cows. $J$. Reprod. Fertil., 113:47-51, 1998.

[46] M. Matsui and A. Miyamoto. Evaluation of ovarian blood flow by colour doppler ultrasound: Practical use for reproductive management in the cow. Vet. J., 181:232-240, 2009.

[47] J. A. McCracken, E. E. Custer, and J. C. Lamsa. Luteolysis: A neuroendocrine-mediated event. Physiol. Rev., 79:263-323, 1999.

[48] M. S. Medan, T. Takedomi, Y. Aoyagi, M. Konishi, S. Yazawa, G. Watanabe, and K. Taya. The effect of active immunization against inhibin on gonadotropin secretions and follicular dynamics during the estrous cycle in cows. J. Reprod. Dev., 52:107-113, 2006.

[49] S. Meier, J. R. Roche, E. S. Kolver, and R. C. Boston. A compartmental model desribing changes in progesterone concentrations during the estrous cycle. J. Dairy Res., 76:249-256, 2009. 
[50] A. Miyamoto, K. Shirasuna, and K. Sasahara. Local regulation of corpus luteum development and regression in the cow: Impact of angiogenic and vasoactive factors. Domest. Anim. Endocrinol., 37:159-169, 2009.

[51] G. D. Niswender, J. L. Juengel, P. J. Silva, M. K. Rollyson, and E. W. McIntush. Mechanisms controlling the function and life span of the corpus luteum. Physiol. Rev., 80:1-29, 2000.

[52] U. Nowak and P. Deuflhard. Numerical identification of selected rate constants in large chemical reaction systems. Appl. Numer. Math., 1:59-75, 1985.

[53] U. Nowak and L. Weimann. NLSCON, Nonlinear Least Squares with nonlinear equality CONstraints, 1993-2004. http://www.zib.de/Numerik/ numsoft/CodeLib/nonlin.en.html.

[54] A. M. Padula and K. L. Macmillan. Oestradiol- $17 \beta$ responsiveness, plasma LH profiles, pituitary LH and FSH concentrations in long-term ovariectomised holstein cows at $24 \mathrm{~h}, 48 \mathrm{~h}$ and 21 days following treatment with an absorbable gnrh agonist implant. Anim. Reprod. Sci., 85:27-39, 2005.

[55] K. I. Parker, D. M. Robertson, N. P. Groome, and K. L. Macmillan. Plasma concentrations of inhibin A and follicle-stimulating hormone differ between cows with two or three waves of ovarian follicular development in a single estrous cycle. Biol. Reprod., 68:822-828, 2003.

[56] A. J. Pawson and A. S. McNeilly. The pituitary effects of GnRH. Anim. Reprod. Sci., 88:75-94, 2005.

[57] G. Perry. The bovine estrous cycle, 2004. http://agbiopubs.sdstate. edu/articles/FS921A.pdf.

[58] R. C. Perry, L. R. Corah, G. H. Kiracofe, J. S. Stevenson, and W. E. Beal. Endocrine changes and ultrasonography of ovaries in suckled beef cows during resumption of postpartum estrous cycles. J. Anim. Sci., 69:2548$2555,1991$.

[59] J. E. Pryce, M. Royal, P. C. Garnsworthy, and I. L. Mao. Fertility in the high-producing dairy cow. Livest. Prod. Sci., 86:125-135, 2004.

[60] I. Reinecke. Mathematical Modeling and Simulation of the Female Menstrual Cycle. PhD thesis, Freie Universitt Berlin, 2008.

[61] I. Reinecke and P. Deuflhard. A complex mathematical model of the human menstrual cycle. J. Theor. Biol., 247:303-330, 2007.

[62] J. F. Roche. The effect of nutritional management of the dairy cow on reproductive efficiency. Anim. Reprod. Sci., 96:282-296, 2006.

[63] J.B. Roelofs, F. J. C. M. van Eerdenburg, N. M. Soede, and B. Kemp. Various behavioral signs of oestrus and their relationship with time of ovulation in dairy cattle. Theriogenology, 63:1366-1377, 2005. 
[64] J. D. Savio, L. Keenan, M. P. Boland, and J. F. Roche. Pattern of growth of dominant follicles during the oestrous cycle of heifers. J. Reprod. Fertil., 83:663-671, 1988.

[65] D. Schams and B. Berisha. Steroids as local regulators of ovarian activity in domestic animals. Domest. Anim. Endocrinol., 23:53-65, 2002.

[66] A. Shaham-Albalancy, Y. Folman, M. Kaim, M. Rosenberg, and D. Wolfenson. Delayed effect of low progesterone concentrations on bovine uterine PGF2 $\alpha$ secretion in the subsequent oestrous cycle. Reproduction, 122:643648, 2001.

[67] W.J. Silvia, G. S. Lewis, J. A. McCracken, W. W. Thatcher, and L. Wilson Jr. Review: Hormonal regulation of uterine secretion of prostaglandin F2 $\alpha$ during luteolysis in ruminants. Biol. Reprod., 45:655-663, 1991.

[68] D. J. Skarzynski, J. J. Jaroszewski, and K. Okuda. Luteotropic mechanisms in the bovine corpus luteum: Role of oxytocin, prostaglandin F2 $\alpha$, progesterone and noradrenaline. J. Reprod. Dev., 47:125-137, 2001.

[69] D. C. Skinner, N. P. Evans, B. Delaleu, R. L. Goodman, P. Bouchard, and A. Caraty. The negative feedback actions of progesterone on gonadotropinreleasing hormone secretion are transduced by the classical progesterone receptor. Proc. Natl. Acad. Sci. U.S.A., 95:10978-10983, 1998.

[70] T. K. Soboleva, A. J. Peterson, A. B. Pleasants, K. P. McNatty, and F. M. Rhodes. A model of follicular development and ovulation in sheep and cattle. Anim. Reprod. Sci., 58 58:45-57, 2000.

[71] G. H. Stabenfeldt, L. L. Ewing, and L. E. McDonald. Peripheral plasma progesterone levels during the bovine oestrous cycle. J. Reprod. Fertil., 19:433-442, 1969.

[72] C. Stocco, C. Telleria, and G. Gibori. The molecular control of corpus luteum formation, function, and regression. Endocr. Rev., 28:117-149, 2007.

[73] C. Taylor and R. Rajamahendran. Follicular dynamics and corpus luteum growth and function in pregnant versus nonpregnant cows. J. Dairy Sci., 74:115-123, 1991.

[74] T. R. Troxel and D. J. Kesler. The effect of progestin and GnRH treatments on ovarian function and reproductive hormone secretions of anestrous postpartum suckled beef cows. Theriogenology, 21:699-711, 1984.

[75] R. F. Veerkamp, B. Beerda, and T. van der Lende. Effects of genetic selection for milk yield on energy balance, levels of hormones, and metabolites in lactating cattle, and possible links to reduced fertility. Livest. Prod. Sci., 83:257-275, 2003.

[76] J. Vizcarra, R. P. Wettemann, T. D. Braden, A. M. Turzillo, and T. M. Nett. Effect of gonadotropin-releasing hormone $(\mathrm{GnRH})$ pulse frequency on serum and pituitary concentrations of luteinizing hormone and folliclestimulating hormone, GnRH receptors, and messenger ribonucleic acid for gonadotropin subunits in cows. Endocrinology, 139:594-601, 1997. 
[77] J. A. Vizcarra, R. P. Wettemann, and G. L. Morgan. Influence of dose, frequency, and duration of infused gonadotropin- releasing hormone on secretion of luteinizing hormone and follicle- stimulating hormone in nutritionally anestrous beef cows. Domest. Anim. Endocrinol., 16:171-181, 1999.

[78] S. L. Walker, R. F. Smith, D. N. Jones, J. E. Routly, and H. Dobson. Chronic stress, hormone profiles and estrus intensity in dairy cattle. Horm. Behav., 53:493-501, 2008.

[79] M. Wiltbank, H. Lopez, R. Sartori, S. Sangsritavong, and A. Gümen. Changes in reproductive physiology of lactating dairy cows due to elevated steroid metabolism. Theriogenology, 65:17-29, 2006.

[80] T. Wise. Biochemical analysis of bovine follicular fluid: albumin, total protein, lysosomal enzymes, ions, steroids and ascorbic acid content in relation to follicular size, rank, atresia classification and day of estrous cycle. J. Anim. Sci., 64:1153-1169, 1987.

[81] D. Wolfenson, G. Inbar, Z. Roth, M. Kaim, A. Bloch, and R. Braw-Tal. Follicular dynamics and concentrations of steroids and gonadotropins in lactating cows and nulliparous heifers. Theriogenology, 62:1042-1055, 2004.

[82] D. Wolfenson, W. W. Thatcher, and M. Drost. Characteristics of prostaglandin $\mathrm{F}$ measurements in the ovarian circulation during the oestrous cycle and early pregnancy in the cow. J. Reprod. Fertil., 75:491-499, 1985 . 